\author{
UNIVERSIDADE DE SÃO PAULO \\ FACULDADE DE ODONTOLOGIA DE BAURU
}

JONAN EMI VALENCIA CARDENAS

Características laríngeas e deglutição em idosos pós-acidente vascular cerebral 
JONAN EMI VALENCIA CARDENAS

\title{
Características laríngeas e deglutição em idosos pós-acidente vascular cerebral
}

\author{
Dissertação apresentada à Faculdade de \\ Odontologia de Bauru da Universidade de São Paulo \\ para obtenção do título de Mestre em Ciências no \\ Programa de Fonoaudiologia, na área de \\ concentração Processos e Distúrbios da \\ Comunicação.
}

Orientadora: Profa. Dra. Giédre Berretin-Felix

BAURU 
Valencia, Jonan

Características laríngeas e deglutição em idoso pósacidente vascular cerebral / Jonan Emi Valencia Cárdenas.

-- Bauru, 2020.

85 p.: il. ; $31 \mathrm{~cm}$.

Dissertação (mestrado) -- Faculdade de Odontologia de Bauru, Universidade de São Paulo, 2020.

Autorizo, exclusivamente para fins acadêmicos e científicos, a reprodução total ou parcial desta dissertação/tese, por processos fotocopiadores e outros meios eletrônicos.

Assinatura:

Data:

Comitê de Ética da FOB-USP

CAAE: 97392318.0 .0000 .5417

Data: $23 / 10 / 2018$ 
ERRATA 

FOLHA DE APROVAÇÃO 



\section{DEDICATORIA}

Aos meus pais Amparo e Emiliano, por sempre estarem me motivando e apoiando no meu caminhar, pelo amor incondicional com os seus filhos, por seus sacrifícios para eu chegar longe, e ser o que sou agora, por ser exemplo de pais compressivos e afetuosos, por me ensinarem a ser sempre uma pessoa prestativa e bondosa para com todos. A vocês pais... os devo tudo! Amo vocês! 


\section{AGRADECIMENTOS}

A meus pais Amparo e Emiliano, meus irmãos, Sandra, Martha, Lorena, Yuli, Emanuel e Nicol por serem pessoas maravilhosas e por me motivarem sempre.

A minha Tia Rosa e Dona Gloria por me escutar e aconselhar tempo todo.

A minhas mães adotivas Luz Da e Alicia e minha segunda família Villabon por me cuidar desde a distância.

Aos meus amigos, Paolha, Estefania e Vivi que sempre ficaram nos meus fracassos e meus sucessos.

Aos meus amigos que se tornaram irmãos, Lorena e Mauricio e dona Isabel por ser tão fofa e aguentar minhas besteiras e me aceitar sem preconceito algum. Gratidão por ser tornarem minha família neste tempo. Amo vocês!

A minha família Brasileira, Mechis, Vânia, Demétrius, Ana Paula, Jonathan, Deborah, André, Carol, Pamela, Diego Vitor, Matheus, Artur por me oferecerem uma amizade incondicional e de muitas alegrias e desde o começo.

Ao meu grão amigo Leonardo Villabon, por me ensinar um novo mundo, uma nova cultura, por me motivar a chegar mais longe dos meus limites.

À minha orientadora Giédre Berretin-Felix, pela oportunidade de eu aprender do seu lado, sem condição alguma, por sua paciência e compreensão. Gratidão por me ajudar a se realizar um sonho, por me permitir eu fazer parte da sua vida e por ser essa motivação para eu me apaixonar por minha profissão! Gratidão! 
As professoras Alcione Ghedini Brasolotto e Kelly Cristina Alves Silvério por dispensar tempo e pela imensa contribuição no meu conhecimento e tamanha ajuda na minha pesquisa. Gratidão!

A minhas colegas fonoaudiólogas Raquel Rodrigues Rosa e Gabriele de Luccas, por serem pessoas prestativas demais e por compartilhar de suas experencia no meu desenvolvimento como profissional, além da contribuição sem condições com minha pesquisa. Gratidão!

Ao departamento de Fonoaudiologia, secretarias Karina, Claudinha, Teka, secretárias das pósgraduações e Leila pela paciência e me ajudar quando sempre precisei. Gratidão!

À Faculdade de odontologia de Bauru da Universidade de São Paulo, por me permitir estar e aprender com os melhores!! Gratidão!! A todos aqueles que fizeram parte desse processo tão importante para minha vida.

O presente trabalho foi realizado com o apoio da Coordenação de Aperfeiçoamento de pessoal de Nível Superior - Brasil (CAPES) - Código de Financiamento 001. 



\section{RESUMO}

O acidente vascular cerebral (AVC) é uma alteração neurológica com maior indecência na população idosa a nível mundial e no Brasil. Tem como sequelas alterações motoras, de comunicação e alimentação, como disfagia, disartria e disfonia, as quais podem acontecer associadas ou isoladamente. Poucos os estudos relacionam as alterações de voz e deglutição após o AVC, principalmente em idosos. Assim, o objetivo deste trabalho foi verificar as relações entre as características laríngeas (morfológicas e funcionais fonatória) e da de deglutição (segurança e eficiência) em idosos pós-acidente vascular cerebral. Estudo retrospectivo em que foram analisados dados de 24 prontuários de pacientes atendidos na Clínica de Fonoaudiologia da Faculdade de Odontologia de Bauru, a saber: gravações dos exames de videoendoscopia da fonação e deglutição realizados previamente à intervenção fonoaudiológica. Foram considerados critérios de inclusão ter diagnóstico médico de AVC e 60 anos de idade ou mais e excluídos pacientes com histórico de doenças oncológicas. Os dados foram analisados considerando assimetria laríngea, arqueamento da porção membranosa, aumento de volume das pregas vestibulares, a classificação do fechamento glótico e a presença de constrição mediana e anteroposterior durante a fonação. Para a deglutição foram consideradas a escala de penetração e aspiração, a escala de resíduos em valéculas, faringe e seios piriformes. Os dados foram tabulados para posterior análise estatística por meio dos testes Mann-Whitey e Kruskal-Wallis, considerando nível de significância de 5\%. Evidenciou-se nos resultados da videoendoscopia da fonação que $91,7 \%$ dos pacientes apresentaram arqueamento da porção membranosa das pregas vocais e aumento do volume das pregas vestibulares, $87,5 \%$ constrição anteroposterior das aritenoides e $62,5 \%$ constrição mediana. Os resultados da avaliação da deglutição demonstraram que $12,5 \%$ dos casos apresentaram penetração, $8,3 \%$ aspiração, sendo que em $33,3 \%$ dos pacientes houve presença de resíduos em seios piriformes com consistência líquida, como também em valéculas para $29,2 \%$ na deglutição de pudim. Verificou-se relação estatisticamente significante entre a escala penetração/aspiração e constrição anteroposterior de aritenoides $(p=0,047)$; entre escala de resíduos em valéculas e assimetria das pregas vocais $(p=0,009)$, aumento das pregas vestibulares $(p=0,040)$ e cobertura da epiglote $(p=0,017)$; entre a escala de resíduos faríngea e assimetria das pregas vocais $(p=0,048)$, aumento das pregas vestibulares $(p=0,020)$ e constrição anteroposterior de aritenoides $(p=0,032)$. Concluiu-se que a característica fonatória constrição anteroposterior apresentou relação com aspectos de segurança e eficiência da deglutição, enquanto os aspectos assimetria de pregas vocais, quantidade de cobertura da epiglote e aumento das pregas vestibulares mostraram relação com a eficiência da deglutição em idosos na fase tardia do acometimento cerebral. 


\section{ABSTRACT \\ Laryngeal and swallowing characteristics in patients affected by stroke}

The cerebrovascular accident (CVA) is the most common neurological disorder in the elderly population worldwide and in Brazil. Its sequels are motor, communication and feeding changes, such as dysphagia, dysarthria and dysphonia, which can occur associated or isolated. Few studies have related voice and swallowing changes after stroke in the elderly. Thus, the objective of this study was to verify the relationship between the morphofunctional characteristics of the larynx and aspects of swallowing safety and efficiency in elderly people after stroke. Retrospective study in which data were analyzed from 24 medical records of patients seen at the Speech Therapy Clinic of the Faculty of Dentistry of Bauru, namely: recordings of the phonological and swallowing videoendoscopy exams performed prior to the speech therapy intervention. To have a medical diagnosis of stroke and 60 years of age or older were Inclusion criteria while patients with a history of oncological diseases were excluded.The data were analyzed considering laryngeal asymmetry, arching of the membranous portion, increased volume of the vestibular folds, the classification of glottic closure and the presence of median and anteroposterior constriction during phonation. The data were tabulated for further statistical analysis using the Mann-Whitey and Kruskal-Wallis tests, considering statistically significant at the 5 percent level. In the phonation videoendoscopy it was observed that $91.7 \%$ of the patients presented arching of the membranous portion of the vocal folds and an increase in the volume of the vestibular folds, $87.5 \%$ anteroposterior constriction of the arytenoids and $62.5 \%$ median constriction. The results of the swallowing evaluation demonstrated that $12.5 \%$ of the cases had penetration, $8.3 \%$ aspiration. In $33.3 \%$ of the patients there was presence of residuals in liquid consistency pyriform sinuses, as well as in the valecule in the pudding swallow for $29.2 \%$ of the individuals. There was a statistically significant relationship between the penetration/aspiration scale and anteroposterior constriction of arytenoids $(p=0.047)$; between scale of residues in vallecule and vocal fold asymmetry $(p=0.009)$, increase in volume of vestibular folds $(p=0.040)$ and epiglottis coverage $(p=0.017)$; between the pharyngeal residue scale and vocal fold asymmetry $(p=0.048)$, increased in volume of vestibular folds $(p=0.020)$ and anteroposterior arytenoid constriction $(p=0.032)$. It was concluded that the anteroposterior constriction phonatory characteristic was related to aspects of safety and efficiency of swallowing, while the aspects of vocal fold asymmetry, amount of epiglottis coverage and increased vestibular folds showed a relation with swallowing efficiency in the elderly in the late phase. of cerebral involvement.

Keywords: cerebrovascular accident (CVA), elderly, swallow, larynx 


\section{LISTA DE QUADROS}

Quadro 1 - Escala de Penetração-Aspiração de Rosenbek et al. (1996).........

Quadro 2 - $\quad$ Escala Yale do resíduo em valéculas

Quadro 3 - Escala Yale do resíduo em seios piriformes.

Quadro 4 - Escala de resíduos em faringe proposta por Kelly et al. (2006) .... 



\section{LISTA DE TABELAS}

Tabela 1 - Dados dos indivíduos quanto ao gênero, idade, tempo do acontecimento do AVC e número de episódios do acometimento.

Tabela 2 - Valores médios de Kappa obtidos por meio da análise da concordância interjuízes para a morfologia da laringe.

Tabela 3 - Valores médios de Kappa obtidos por meio da análise da concordância interjuízes para 0 comportamento laríngeo fonatório

Tabela 4 - Valores médios de Kappa obtidos por meio da análise da concordância interjuízes para as escalas da deglutição nas diferentes consistências alimentares.

Tabela 5 - Categorização morfológica da laringe em repouso segundo os achados do exame de videoendoscopia

Tabela 6 - Categorização do comportamento laríngeo durante a fonação da vogal "i"

Tabela 7- Resultados da escala de Penetração-Aspiração de acordo à videoendoscopia da deglutição

Tabela 8 - $\quad$ Achados da videoendoscopia da deglutição para resíduos em valécula, faringe e seios piriformes

Tabela 9 - Relação entre morfologia laríngea e a escala de PenetraçãoAspiração

Tabela 10 - Relação entre comportamento laríngeo e a escala de PenetraçãoAspiração

Tabela 11- Relação entre morfologia laríngea e a escala de resíduos em valéculas

Tabela 12 - Relação entre comportamento laríngeo fonatório e a escala de resíduos em valéculas. 

Tabela 13 - Relação entre morfologia laríngea e a escala de resíduos em seios

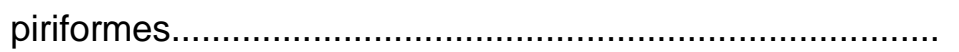

Tabela 14 - Relação entre o comportamento laríngeo fonatório e a escala de resíduos em seios piriformes.

Tabela 15 - Relação entre morfologia laríngea e a escala de resíduos em

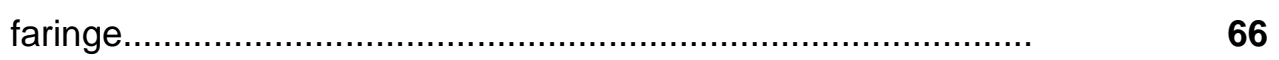

Tabela 16 - Relação entre comportamento laríngeo fonatório e a escala de resíduos em faringe. 



\section{LISTA DE ABREVIATURAS E SIGLAS}

AVC Acidente vascular cerebral

VEL Videoendoscopia da laringe

VEF Videoendoscopia da Fonação

VED Videoendoscopia da deglutição

n

Número de pacientes

RV Resíduos em Valéculas

RSP Resíduos em Seis Piriformes

RF Resíduos em Faringe 

$1 \quad$ INTRODUÇÃO

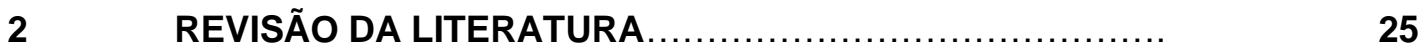

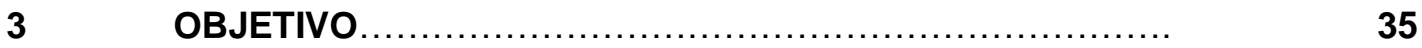

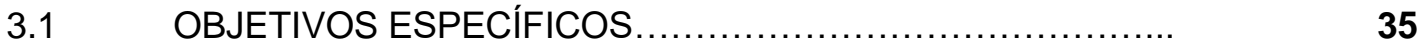

$4 \quad$ CAUÍSTICAS E MÉTODOS .................................. 39

4.1 Tipo de estudo e Aspectos éticos …..................................... 39

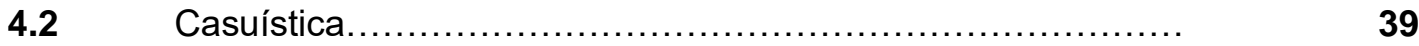

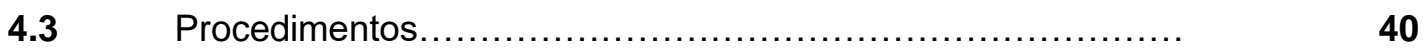

4.3.1 Videoendoscopia da fonação e da deglutição .......................... 40

4.3.1.1 Análises da Fonação a partir do exame da nasoendoscopia.... 41

4.3.1.2 Análises da Deglutição a partir do exame da nasoendoscopia............................................................... 42

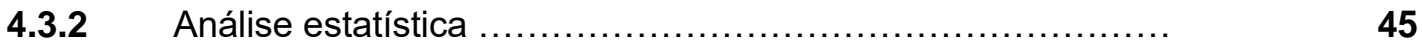

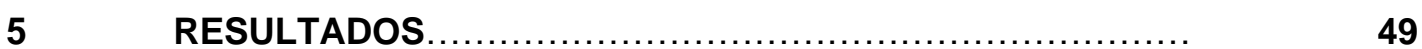

$5.1 \quad$ Videoendoscopia da Fonação …........................... 49

$5.2 \quad$ Videoendoscopia de Deglutição................................. 50

5.3 Relação e correlação entres os características de deglutição e fonação........................................................ 53

6

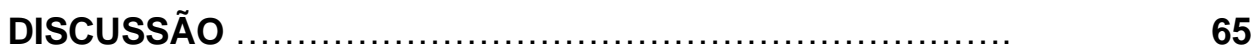

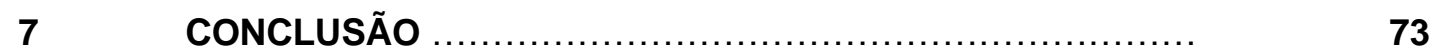

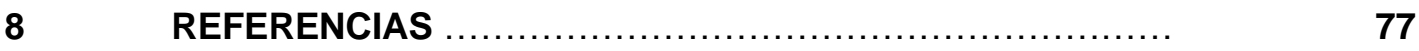

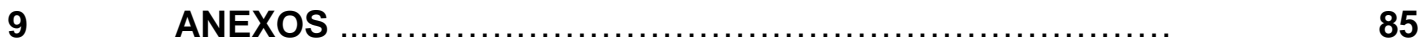




Introdução 


1. INTRODUÇÃO

Segundo a organização mundial da saúde (2015), os acidentes vasculares cerebrais (AVC) são fenômenos agudos decorrentes de obstáculos que impedem que o sangue fluxa até o cérebro. Uma definição mais especifica é a alteração na qual uma área do encéfalo é afetada transitória ou permanentemente por uma isquemia ou hemorragia. A isquemia ocorre devido à diminuição do fluxo sanguíneo cerebral, podendo ser global ou focal, esta última se apresenta como um acidente isquêmico transitório que se pode estabilizar ou não antes de 24 horas. A hemorragia cerebral pode ser definida como o aumento de sangre no parênquima ou no interior dos ventrículos cerebrais e espaço subaracnóideo, trazendo como consequências déficit cognitivo leve ou moderado e até morte cerebral (DÍEZ et al., 2001), representando uma das principais causas de morte e incapacitação física em todo o mundo desenvolvido (DE MAGALHÃES; FRANCO, 2001).

Thriftet al. (2017) identificaram que a maior taxa de incidência mundial do acidente cerebrovascular foi observada na Itália, em 2012, correspondendo a $19 \%$ da população total, enquanto que o Japão conta com uma porcentagem de $7.5 \%$ de indivíduos após 65 anos acometidos pelo AVC. Por outro lado, Cazaquistão se posicionou como o país com a maior mortalidade devido ao AVC por ano.

Especificamente no Brasil, a Pesquisa Nacional de Saúde, com base epidemiológica domiciliar, analisou a prevalência de AVC e de incapacidade, cujos resultados mostraram que 2.231 .000 pessoas apresentam AVC e destas 568.000 apresentam deficiências graves e limitações muito severas, com maior prevalência em zonas urbanas, homens, pessoas sem educação formal e, principalmente, em idosos (BENSENOR et al., 2015).

A maioria das alterações cerebrais acometem pessoas em idade acima dos 65 anos, sendo que tais alterações trazem como consequência dificuldades físicas que afetam a mobilidade extremidades superiores ou resultam em quadros de hemiplegia. Também acarretam transtornos de linguagem e fala, como disartria, afasia motora e mista (SUAREZ et al., 2011), além de disfonia e disfagia neurológica (RODRIGUES; JACUVISKE; ZAZO, 2010). 


\section{1-Introdução}

A disfonia é o distúrbio da comunicação oral no qual a voz não consegue cumprir seu papel básico de transmissão da mensagem verbal (BEHLAU, 2001). Nos casos de pacientes com sequelas de AVC, eles apresentam alterações em sua voz como rugosidade, soprosidade, instabilidade e pastosidade, como também diminuição na velocidade e instabilidade na repetição de vogais, não tendo sido encontrada relação entre a localização da lesão neurológica e as características vocais (FERNANDES et al., 2014).

A disfagia é a dificuldade na coordenação dos movimentos de deglutição e esta alteração pode levar à aspiração silenciosa de alimentos e/ou saliva, causando pneumonia com risco de morte (BEZERRA et al., 2010). Especificamente em sequelas de $A V C$, os pacientes apresentam deficiência na fase oral preparatória e sinais de aspiração na fase faríngea; sendo que idosos sem doenças neurológicas também podem apresentar alterações da sensibilidade intraoral; além de ausência de elevação da laringe, dificultando o processo de deglutição (VIANA; OLIVERA; RAMOS, 2010).

A relação entre disfonia e disfagia foi evidenciada no trabalho Weber et. al (2014), que descreve o uso da percepção vocal para comparar mudanças da voz após ingestão de alimentos entre pacientes com e sem diagnósticos de disfagia orofaríngea. A autora encontrou modificações nas características voz após a deglutição, como o aumento do esforço vocal, gerando astenia, descrevendo que o paciente busca equilibrar sua fonação por meio da tensão das pregas vocais devido à presença de resíduo alimentar na laringe.

Outro estudo similar, desenvolvido com participantes diagnosticados com disfagia orofaríngea por sequela de AVC, analisou cinco parâmetros acústicos antes e após a deglutição de bário líquido: frequência fundamental, perturbação média relativa, porcentagem de shimmer, relação ruído-harmônico e índice de turbulência de voz. Não foram identificadas mudanças significativas na voz de modo a determinar aspiração laringotraqueal, uma vez que o líquido atingiu a traqueia sem resultar em revestimento ao nível das pregas vocais, sendo insuficiente para influenciar os resultados da análise acústica (CHANG et al. 2012). 
Os estudos anteriores demostram que existe relação entre disfagia e transtornos da voz, mas são poucas as pesquisas que descrevem essa relação em pacientes idosos diagnosticados com AVC. Marrara (2010) caracterizou a voz de pacientes neurológicos por meio de avaliação perceptivo-auditiva, acústica e do padrão visual da dinâmica vocal antes e após a deglutição. Nas análises acústicas os pacientes apresentaram rugosidade de grau leve e soprosidade, enquanto $60 \%$ dos participantes apresentaram instabilidade em grau um. Nenhum paciente apresentou qualidade vocal molhada, sendo que estas mudanças na voz confirmaram penetrações no trato vocal comprovadas durante o exame de videofluoroscopia. Campos (2013) encontrou relações entre voz e disfagia em pacientes idosos com AVC, no que diz respeito aos sintomas de cansaço depois de falar e dificuldade para deglutir os alimentos; engasgo durante as refeições e tosse após as refeições; características vocais de soprosidade e astenia com resíduo em valécula para alimentos sólidos.

Diversos estudos descrevem os distúrbios fonoaudiológicos decorrentes das sequelas de AVC. Especificamente pesquisas em voz, fala e deglutição evidenciam as alterações que permitem encaminhar tratamentos mais adequados de acordo à necessidade de cada paciente. Assim, existe a necessidade de fortalecer as avaliações fonoaudiologicas integrais, por meio de ampliação dos conceitos e a relação de voz e disfagia, o que permitirá melhorar a qualidade de vida da população idosa com sequelas de AVC.

Assim, a presente pesquisa tem como hipótese que o envelhecimento determina mudanças anatomofuncionais na laringe e na coordenação neuromuscular de forma geral, sendo que na presença do acometimento vascular cerebral as funções de voz e deglutição podem ser influenciadas por ambas as condições, existindo relação especifica entre os prejuízos encontrados em ambas as funções, tais como entre a segurança (penetração/aspiração) e a eficiência (resíduos) da deglutição com as características morfológicas e o comportamento funcional fonatório da laringe. 




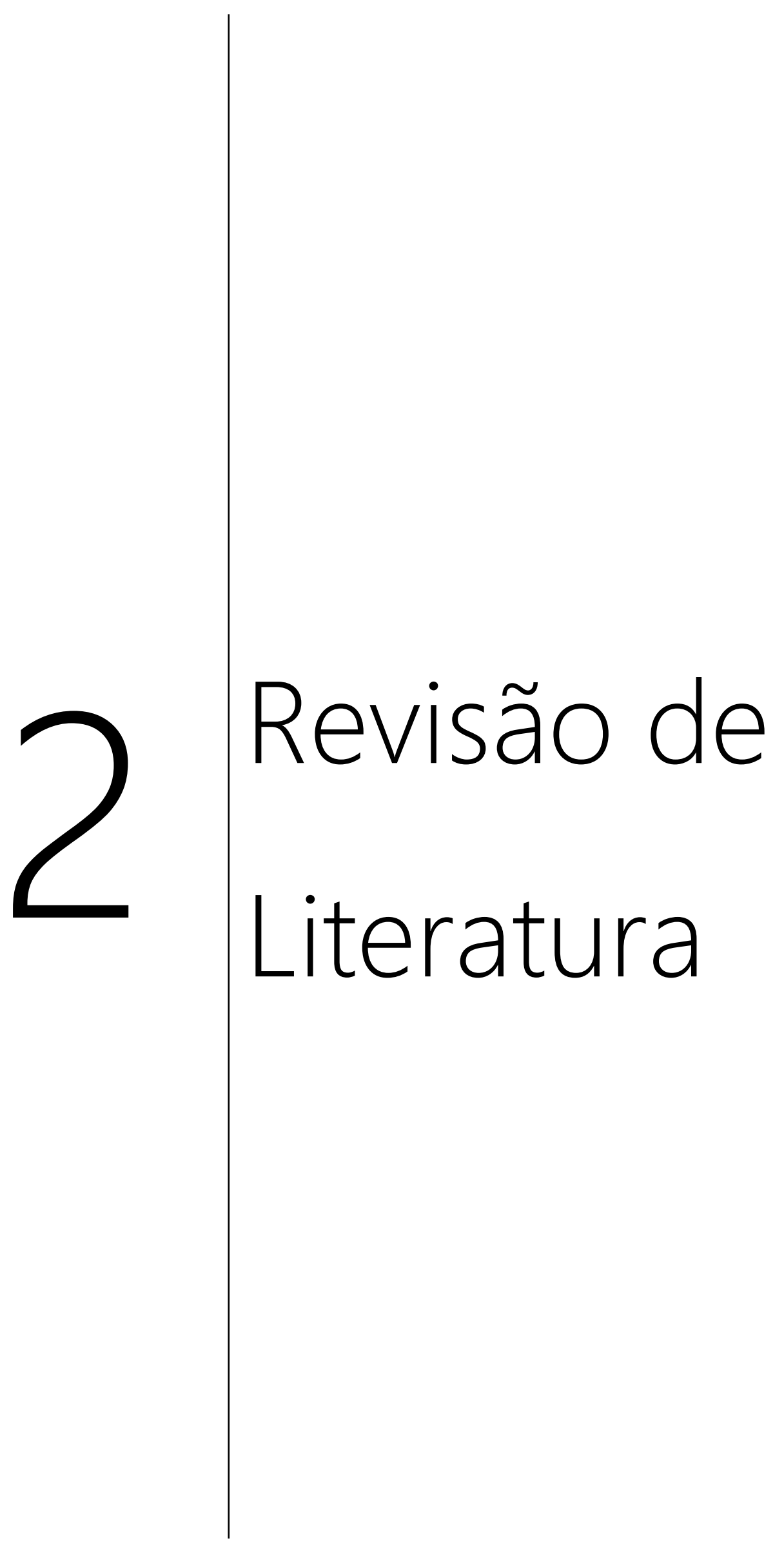







\section{REVISÃO DA LITERATURA}

De acordo com Diez et al., (2001), o AVC pode ser definido como a alteração na qual uma área do encéfalo é afetada por uma isquemia ou hemorragia. A isquemia sucede pela diminuição do fluxo sanguíneo cerebral de modo permanente denominada isquemia global ou temporal denominada isquemia focal, esta última se apresenta como um acidente isquêmico transitório que se pode estabilizar ou não antes de 24 horas com melhor prognóstico no paciente. Outra calcificação é hemorragia cerebral que tem como definição a acrescência de sangre no parênquima ou no interior dos ventrículos cerebrais e espaço subaracnóideo trazendo como consequências que sucedem desde um déficit cognitivo leve ou moderado até morte cerebral.

Magalhães et al. (2001) descreveram a incidência e caraterísticas de acidente vascular cerebral, informando que os AVCs estão entre as principais causas de morte e incapacitação física em todo o mundo desenvolvido. Para o ano 2001, nos Estados Unidos da América, aproximadamente 500 mil pessoas apresentam um AVC novo ou recorrente a cada ano. Dessas, 150 mil morrem anualmente por AVC. A cada ano, 50 mil norte-americanos sofrem ataques isquêmicos transitórios, e quase um terço desses desenvolve subsequentemente um AVC. No Brasil os resultados identificaram 2.231.000 pessoas com AVC e 568.000 com incapacidade grave. Incidência maior em homes, maiores de 65 anos idosos e com pouca educação Bensor et al. (2015).

Suares et al. (2011) estudaram as características clínicas e aspetos sociais em paciente pós AVC atendidos em uma clínica neurológica. Para isso, aplicaram um questionário a 81 pacientes com tempo de egresso de entre seis meses e dois anos, com perguntas de percepção e evolução de estado atual de incapacidade. Foram identificadas sequelas físicas e de linguagem, como transtorno motor em extremidades e disartria, determinando que independentemente da localização cerebral afetada existe um impacto no âmbito laboral da população estudada.

Para complementar a sequelas fonoaudiológicas de AVC, Rodrigues et al. (2010) caracterizaram uma população de pacientes com lesão neurológica descrevendo as queixas e alteração da comunicação num hospital terciário. A 
análise retrospectiva de prontuários de paciente atendidos em cinco anos na Universidade Federal de São Paulo demonstrou que, dos 244 casos atendidos, a maioria foi homens de $42-64$ anos, dos quais $56 \%$ foram diagnosticados com Afasia, seguido, em menor porcentagem, de disartria, disfagia e disfonia.

Um estudo fez descrição das características laríngeas em idosos a partir da avaliação da relação entre a queixa vocal e os indicativos de presbilaringe. Foram 210 idosos, 88 homens e 122 mulheres. Se apresentaram queixas vocais como tosse, desconforto laringofaríngeo, pigarro/secreção e dificuldades de deglutição. Achou-se com mais frequência em homens arqueamento das pregas vocais e saliência nos processos vocais. Também foram encontradas presença de fendas fusiformes durante a fonação. Nas mulheres $28,7 \%$ e nos homens $6,8 \%$ apresentaram aumento da massa das pregas vocais. Os autores concluíram que houve maior ocorrência de queixa vocais na ausência de arqueamento vocal (PONTES, BRASOLOTTO e BEHLAU, 2005).

Averiguar o impacto dos aspetos respiratórios e dos aspetos vocais na qualidade de vida em voz em idosos foi objetivo de pesquisa desenvolvida por Siquera (2013). Participaram 56 idosos acima de 60 anos, observando-se maior porcentagem de ocorrência de ato de pigarrear, falar alto e ter problemas digestivos, além das características laríngeas de arqueamento de prega vocal, fenda glótica fusiforme e constrições supraglóticas. Os idosos em geral, consideraram suas vozes como sendo boas, além de apresentarem eleva do grau de qualidade de vida em voz.

Yamauchi et al. (2012) compararam as características das vibrações das pregas vocais de um grupo de idosos a um grupo de jovens saudáveis para esclarecer as diferenças relacionadas a gênero e idade. As análises foram realizadas a partir de avaliação subjetiva de imagem digital de alta velocidade e a qualidade da voz usando o Escala GRBAS por médicos otorrinolaringologistas. Os resultados demonstraram em uma frequência fundamental de fala que $39 \%$ apresentaram simetria laríngea, 39\% laringe ligeiramente assimétrica e 22\% moderadamente assimétrica; a assimetria revelada não houve diferenças significativas entre os arremessos ou subgrupos, embora tenha sido relativamente 
mais frequente $(75 \%)$ e grave em idosos do sexo masculino em comparação com outros subgrupos. O fechamento glótico foi completo em $62 \%$, incompleto em $9 \%$ e parcial devido ao espaço (gap) glótico em 30\%. Com o fechamento incompleto incluído foram localizadas posteriormente em $72 \%$ e localizadas anteriormente em 28\%. A ocorrência de fechamento incompleto e gap glótico correlacionaram-se positivamente com o pitch $O$ tamanho do espaço glótico (gap) também foi correlacionado positivamente com o aumento do pitch. O gap glótico foi frequente em mulheres jovens (53\%) e mulheres idosas (50\%), e incomum em jovens do sexo masculino (22\%) e idosos do sexo masculino (13\%), embora as diferenças entre os subgrupos insignificantes $(p=0,15)$. Em mulheres jovens, todos os gaps glóticos localizaram-se posteriormente, enquanto nas idosas, $80 \%$ foram localizadas anteriormente. Os resultados mostram que os comportamentos das vibrações das pregas vocais foram diversos mesmo em indivíduos saudáveis com ausência de queixas vocais ou história de doenças laríngeas.

A pesquisa desenvolvida por Fernandes (2014) teve por objetivo descrever as características fonatórias de dez idosos acometidos por AVC, de acordo com a topografia da lesão observada ao exame de neuroimagem. Todos os participantes tiveram amostras de voz gravadas e foi realizada avaliação perceptivo-auditiva da voz e da diadococinesia laríngea. Os exames de neuroimagem foram classificados quanto à localização, extensão, lateralidade e território de vascularização da lesão cerebral. Os resultados mostram uma população acometida por AVCs extensos de artéria cerebral média e AVCs de localização variada no cérebro. As vozes dos sujeitos mostraram predominantemente presença de rugosidade, soprosidade, instabilidade e pastosidade, além de alteração no controle motor laríngeo, demonstrado pela velocidade reduzida e instabilidade na repetição de vogais. Essas características ocorreram tanto no grupo de pacientes com AVC extenso de lesão da artéria cerebral média como em pacientes com AVCs menores de localização variada no cérebro. Os achados sugerem que as manifestações vocais dos casos estudados não dependem apenas da topografia da lesão, sendo importante considerar as individualidades de cada paciente no momento da avaliação clínica.

Especificamente no que se refere ao processo da deglutição, um estudo (EISENHUBER et al., 2002) avaliou o significado clínico da retenção faríngea para predizer presença de aspiração em pacientes com disfagia com média de idade de 
60 anos, com ajuda da videofluoroscopia para avaliar resíduos em valéculas e seios piriformes e o grau de aspiração. Os resultados evidenciaram que a retenção faríngea foi causada por fraqueza ou paresia faríngea na maioria dos pacientes. Também se observou que as aspirações foram presentes em paciente com anormalidades funcionais adicionais, como fechamento laríngeo incompleto ou diminuição da inclinação presença epiglótica. A maioria dos pacientes apresentou retenção faríngea grave (89\%), seguido de aspiração moderada (29\%) e aspirações leve $(25 \%)$. Os autores concluíram que os resíduos faríngeos pós deglutição, além das anormalidades funcionais laríngeas, podem alterar a função do fechamento glótico, causando aspiração.

Andrade et al. (2009) analisou a deglutição de 46 adultos com media de idade de 58,9 anos e alterações neurológicas, por meio de exames de videoendoscopia da deglutição de alimentos nas consistências líquida, pastosa e sólida. Observou-se nos resultados que $62,2 \%$ dos pacientes apresentaram atraso na deglutição e estase em valéculas $(54,1 \%)$ de consistência pastosa e solida, estase nos seios piriformes em $48,6 \%$ e penetração $(40,5 \%)$ e aspiração $(16,2 \%)$ traqueal de líquidos antes da deglutição. Os autores concluíram que as principais manifestações disfágicas observadas estiveram relacionadas às alterações das fases voluntárias da deglutição e ao aumento das consistências dos alimentos.

Outro estudo (CHEN et al. 1990) avaliou a localização e a gravidade da disfunção da deglutição em 46 pacientes com doença cerebrovascular, submetidos a exame videofluoroscópico com alimentos de várias consistências. Dificuldades leves de deglutição ocorreram em 18 pacientes (39\%), disfunção moderada em $23(50 \%)$ e disfunção grave em cinco (11\%). Trinta e um pacientes apresentaram estase em faringe, tendo sido assimétrica em 25 deles (81\%), enquanto três apresentaram estase do lado direito, e outros três do lado esquerdo. A estase assimétrica não se correlacionou com a localização da doença cerebrovascular. Foi encontrada aspiração em 24 pacientes, metade deles com alimentos de baixa viscosidade. Assim, a videofluoroscopia pode ser usada para definir a localização e gravidade das anormalidades orofaríngeas, o que é fundamental para as recomendações 
alimentares. As anormalidades presentes, no entanto, não foram úteis na predição do tipo de doença cerebrovascular.

Viana et al. (2010) analisam a deglutição em 26 paciente entre 26 a 83 anos, diagnosticados AVC isquêmico e 15 voluntários saudáveis como grupo controle das mesmas idades. Os participantes forma se avaliados com método clínico e cintilográfico da deglutição, utilizando $5 \mathrm{ml}$ de alimento na consistência pastosa e líquida. Os autores demostram que o grupo controle apresentou elevação laríngea ineficiente e sinais clínicos de aspiração em um indivíduo. Na fase oral, foi encontrado preparo ineficiente para a deglutição do líquido em $27 \%$ dos pacientes e para o pastoso em $42 \%$. Na fase faríngea, $12 \%$ apresentaram tosse e engasgo. $\mathrm{Na}$ avaliação cintilográfica os pacientes apresentaram maior quantidade de resíduo oral e menor duração de trânsito faríngeo na deglutição de pastoso, comparado ao grupo controle. Os autores concluíram que a avalição clínica e instrumental e o método cintilográfico são importantes para a reabilitação de paciente com alteração na deglutição com AVC, o que permitiu a quantificação de o tempo de transito, resíduo e tempo de depuração em cada fase da deglutição, estabelecendo-se parâmetros para outros estudos.

Agora um estudo recente (MONTALDI, DANTAS, 2019) tive como objetivo avaliar por videofluoroscopia, o padrão de deglutição em 33 pacientes com AVC isquêmico sem sintomas de disfagia com tempo de acontecimento do AVC de três a cinco meses e 19 voluntários saudáveis. As fases oral e faríngea da deglutição foram avaliadas após deglutição de $5 \mathrm{ml}$ e $10 \mathrm{ml}$ de consistência líquida, pastosa e solida. Os resultados apresentaram maior frequência de movimento da cabeça, deglutições múltiplas, escape prematuro e resíduo em valéculas da consistência liquida comparado com o grupo controle. Não houve diferença entre pacientes e voluntários no trânsito oral e faríngeo, exceto por uma preparação oral mais longa para o líquido de $5 \mathrm{~mL}$ em pacientes. Alterações na deglutição causadas por aumentos no volume da consistência não foram diferentes entre pacientes e voluntários. Os pesquisadores concluíram que não foram encontradas alterações significativas na dinâmica da deglutição em pacientes sem sintomas de disfagia e sem restrição de ingestão de alimentos três meses após a isquemia. 
Weber et al. (2014) descreveram a detecção de disfagia com ajuda de análises de voz perceptual com a participação de 27 pessoas com diagnósticos de disfagia e $25 \mathrm{com}$ normalidade. Foi realizado o registro sustentado de vogal /a/ antes e despois de ingestão de alimento pastoso, líquido e sólido. Para determinar as mudanças de voz foi utilizada a escala de GRBAS que analisa os aspectos de rugosidade, respiração, astenia e tensão. Outro parâmetro utilizado para a análise foi a voz molhada. Os autores encontraram relação significativa entre grau de desvios da voz, astenia e aumento na tensão após a deglutição de alimento pastoso, determinando que os fatores encontrados são indicativos de transtorno da deglutição.

$\mathrm{Na}$ pesquisa desenvolvida por Chang et al. (2012), os autores identificaram aspirações e penetrações durante a deglutição de bário líquido, por meio do exame de videofluoroscopia, e analisaram a presença de mudanças da qualidade vocal. Participaram 44 pacientes com transtorno da deglutição que realizaram avaliação da produção de vogal /a/ antes e despois de engolir $5 \mathrm{ml}$ de bário líquido, tendo sido analisados cinco parâmetros acústicos que incluem a frequência fundamental, perturbação relativa, Shimmer, relação ruído - harmônico e o índice de turbulência de voz. Não foram encontradas mudanças significativas na voz, uma vez que o bário líquido fluía facilmente em direção a traqueia, sem desenvolver um revestimento nas pregas vocais, sendo insuficiente para a detecção de mudanças no padrão vocal.

Marrara (2014) buscou caracterizar a mostra vocal de pacientes disfásicos, antes e após a deglutição e $3 \mathrm{ml}$ e $7 \mathrm{ml}$ da consistência patosa e líquida, utilizando a análise perceptivo auditiva e acústica tradicional e do padrão visual da dinâmica vocal. Participaram da pesquisa 31 pacientes, sendo 26 com diagnósticos neurológicos e 5 saudáveis para o grupo controle. $\mathrm{Na}$ análise perceptiva auditiva a tensão e instabilidade foram mais sensíveis para a presença de resíduo e penetração laríngea, enquanto para aspiração foi associada à rugosidade. As técnicas permitiram uma avaliação qualitativa para a análise da voz na identificação de problemas neurológicos como a disfagia orofaríngea.

Gomes (2004) buscou compreender as mudanças na qualidade vocal em produções orais em duas mulheres e um homem com disfagia pós AVE, realizando 
associação entra as características dos processos da deglutição e da fala. Usaram como metodologia a avaliação perceptiva com e sem implicação da deglutição em consistências liquida e pastosa durante a avaliação videoendoscópica da deglutição. Os resultados demonstraram que pacientes com disfagia realizaram mobilizações no plano laríngeo (fonatório) e supralaríngeo (articulatório) como possível mecanismo de proteção das vias aéreas durante a deglutição, que guardam semelhança com a atividade fisiológica da fase faríngea da deglutição e da produção dos sons faríngeos. Do ponto de vista acústico, ressalta-se a validade da análise da frequência fundamental, do traçado da forma da onda, da estrutura harmônica, padrão dos formantes. Como relevantes para o levantamento de hipóteses relacionadas à presença de resíduos do bolo alimentar ou saliva na região glótica e/ou supraglóticas, penetração laríngea e risco de aspiração, associadas com a percepção auditiva do que é referido como voz molhada.

Campos (2013) investigou a relação entre voz e disfagia em pacientes idosos acometidos por AVC. Para isso realizou um estudo retrospectivo em que participaram 30 indivíduos, sendo 14 mulheres e 16 homens, com idades entre 61 e 90 anos, considerando os resultados obtidos por meio das queixas de deglutição e voz, da analise perceptivo auditiva da voz com a escala GRBASI, videoendoscopia da deglutição para analisar o grau da disfagia e identificar penetração ou aspiração. Foi encontrada relação entre sintomas de cansaço depois de falar muito e dificuldade para deglutir os alimentos, engasgo durante as refeições e tosse após as refeições. Também houve correlação entre estase em valécula para a consistência sólida e as características vocais de soprosidade e astenia, relação entre gravidade dos sinais de alteração da deglutição com a configuração laríngea.

O estudo realizado por Altman et al. (2007) a partir de revisão de literatura tiveram como objetivo descrever as alterações da voz num grupo significativo de pacientes acometidos por AVC e com disartria. Os autores encontraram que a voz e as alterações de fala nessa população são complexas e altamente dependentes da localização da lesão no cérebro especificamente nas áreas da fala e linguagem. De acordo com os autores, uma das alterações mais comum nesta população é a disartria com incidência entre $8 \%$ a $30 \%$ seguido da imobilidade e paresia de prega vocal. As mudanças de voz e fala, comuns com lesão do neurônio motor (espasticidade), são caracterizadas por articulação desacelerada, qualidade sonora 
tensa, e hipernasalidade. Contrariamente, as lesões do neurônio motor inferior (flácidas) resultam em perda de tônus muscular, de reflexos, soprosidade na qualidade de voz com volume diminuído e desperdício de ar. Os autores concluíram que a recuperação da disartria é dependente da recuperação geral da lesão neurológica, sendo que esta última determina o prognóstico.

De acordo com a literatura, pacientes diagnosticados com AVC apresentam alterações nas fases oral e faríngea da deglutição, além de alterações significativas na voz. Porém, poucos estudos buscam compreender o relacionamento entre as alterações de voz e deglutição em idosos após o AVC. 


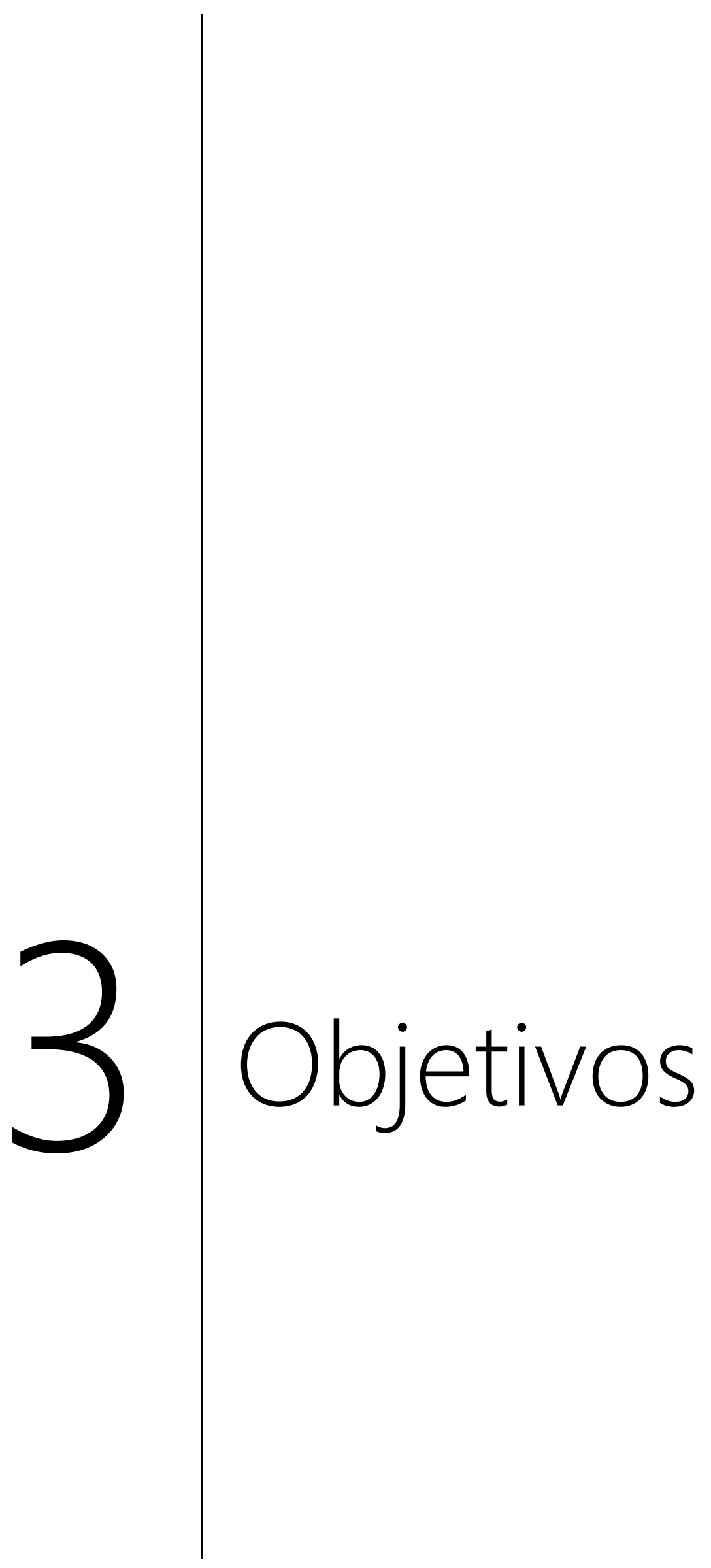







\section{OBJETIVOS}

\subsection{Objetivo Geral}

O objetivo deste trabalho foi verificar as relações entre as características morfofuncionais laríngeas e aspectos de segurança e eficiência da deglutição em idosos pós-acidente vascular cerebral.

\subsection{Objetivos Específicos}

- Verificar a relação entre as características morfológicas e o comportamento fonatório da laringe com a severidade da aspiração/penetração.

- Verificar a relação entre as características morfológicas e comportamento fonatório da laringe com o nível de resíduos em valéculas, na faringe e em seios piriformes. 




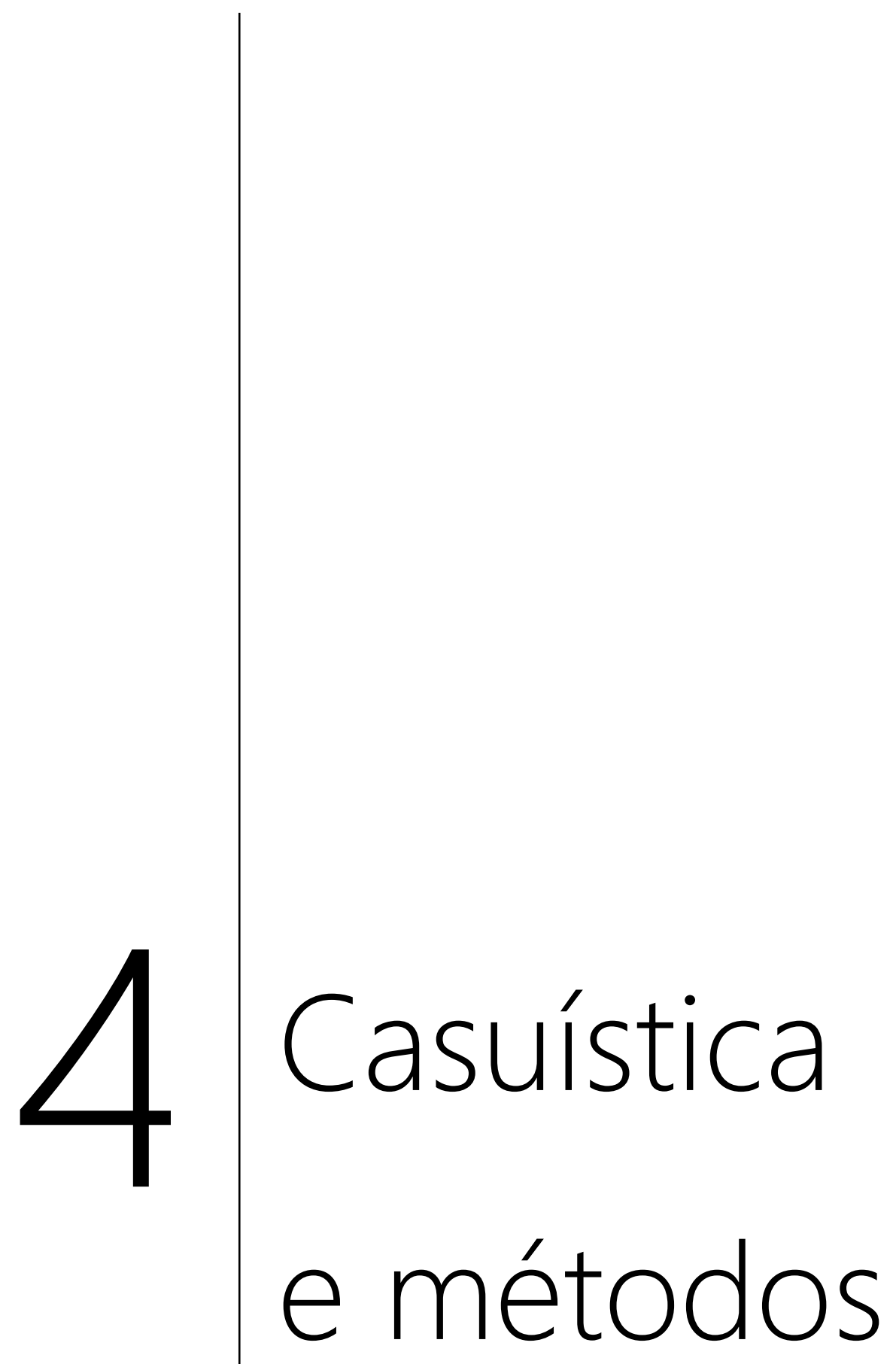






\section{CASUÍSTICA E MÉTODOS}

4.1Tipo de Estudo e Aspectos Éticos:

Para realização da presente pesquisa de tipo retrospectivo, o projeto foi enviado e aprovado pelo do Comitê de Ética em Pesquisa com Seres Humanos (CEP) da Faculdade de Odontologia de Bauru da Universidade de São Paulo (FOB/USP), com número de aprovação 97392318.0.0000.5417 e aprovação da dispensa do termo de consentimento livre e esclarecido (ANEXO 1).

Foram respeitados os critérios éticos durante tudo o período de execução da pesquisa, sendo garantido a não exposição dos dados dos pacientes, bem como o zelo e cuidado com os arquivos dos prontuários.

\subsection{Casuística:}

Foram analisados 35 prontuários e exames de videoasoendoscopia da fonação do banco de dados da Clínica de Fonoaudiologia da Faculdade de Odontologia de Bauru da Universidade de São Paulo (FOB/USP).

Para os critérios da inclusão foram selecionados indivíduos independente do gênero, com idade igual o superior a 60 anos; diagnóstico médico de AVC; tempo mínimo da doença de seis meses; condição de saúde estável e ausência de outro tipo de doenças como oncológicas, psiquiátricas, cardíacas, respiratórias, genéticas, sindrômicas e/ou traumas de cabeça e pescoço adquiridos.

Após aplicação dos critérios de inclusão, foram selecionados 24 indivíduos com idade acima de 60 anos; sendo 8 mulheres e 16 homens; com diagnóstico médico de acidente vascular cerebral, sendo 3 indivíduos de tipo hemorrágico e 21 de tipo isquêmico; com tempo de lesão entre 6 meses e 276 meses (média 62,96 meses). Com relação ao número de episódios de AVC, 18 indivíduos apresentaram 1 episódio, 4 indivíduos apresentaram 2 episódios e 2 indivíduos apresentaram 3 episódios, como apresentado na Tabela 1. 
Tabela 1. Dados dos indivíduos quanto ao gênero, idade, tempo do acontecimento do AVC e número de episódios do acometimento.

\begin{tabular}{|c|c|c|c|c|c|c|c|c|c|c|}
\hline & \multicolumn{2}{|c|}{ Sexo } & \multicolumn{2}{|c|}{ Tipo AVC } & \multicolumn{3}{|c|}{$\begin{array}{l}\text { Tempo do acontecimento } \\
\text { em meses à data do exame }\end{array}$} & \multicolumn{3}{|c|}{ Número de episódios } \\
\hline & Feminino & Masculino & Isquêmico & Hemorrágico & Mínimo & Média & Máxima & 1 & 2 & 3 \\
\hline Frequência & 8 & 16 & 21 & 3 & 6 & 62,96 & 276 & 18 & 4 & 2 \\
\hline Porcentagem & $33,3 \%$ & $66,7 \%$ & $87,5 \%$ & $12,5 \%$ & --- & --- & --- & $75,0 \%$ & $16,7 \%$ & $8,3 \%$ \\
\hline
\end{tabular}

\subsection{Procedimentos:}

\subsubsection{Videoendoscopia da deglutição e fonação}

O exame clínico de videoendoscopia foi realizado para avalição das funções de fonação e deglutição, tendo sido conduzido por um médico otorrinolaringologista em cooperação com um fonoaudiólogo com doutorado e pós-doutorado na área de distúrbios da deglutição.

Ao começo da videoendoscopia os pacientes foram instruídos para permanecer sentados, com a cabeça disposta na direção de eixo corporal, sem flexão ou rotação. Utilizou-se como equipo de avaliação um Rinolaringofibroscopio Padrão ENF-P4, fonte de luz halógena CHL-25, câmera OTV-SC, todos da marca Olympus para nasofibroscoscopia da deglutição e da laringe. Os registros das imagens foram gravados em um DVD Philips. Sobre a circunferência da fibra ótica flexível aplicou-se xilocaína gel, para não gerar desconforto na cavidade nasal no tempo de sua introdução.

Para a avalição da função da laringe em fonação e repouso durante a videoendoscopia, os pacientes foram instruídos para respirar sem emitir algum som, 


\section{Casuística e Métodos}

para observas as estruturas laríngeas em repouso e depois realizar a emissão da vogal /i/ de forma sustentada.

Para a deglutição foi solicitada a ingesta de alimentos categorizados em três tipos de consistências e coloridos artificialmente com anilina azul, sendo: água filtrada medida por uma seringa de $10 \mathrm{ml}$, depositado o conteúdo num copo plástico (capacidade de $50 \mathrm{ml}$ ); alimento pastoso preparado a partir de $2 \mathrm{~g}$ de pó de suco de uva dietético (Clight) adicionado em um copo plástico (capacidade de $200 \mathrm{ml}$ ) com $30 \mathrm{ml}$ de água, engrossado com uma medida de espessante instantâneo NUTILIS, chegando a uma consistência final semelhante ao pudim; alimento sólido, correspondendo a uma fatia de pão de agua de $1 \mathrm{~cm}$ de espessura e aproximadamente $4 \mathrm{~cm}$ de diâmetro (SILVA, 2002; BERRETIN-FELIX, 2005; FIORAVANTI, 2007).

Os pacientes foram orientados a colocar o conteúdo líquido na boca e engolilo somente após orientação verbal da avaliadora; para a consistência pastosa foi feito o mesmo. Na consistência solida o alimento foi introduzido na cavidade oral do paciente e solicitado ao mesmo para realizar a mastigação, organização e deglutição do bolo alimentar de forma habitual.

4.3.1.1 Análise da laringe a partir do exame de videooendoscopia

As análises dos exames foram realizadas por duas fonoaudiólogas com título doutor, especialistas na área de distúrbios da voz, devidamente treinadas e calibradas. O treinamento foi realizado por meio da análise de exames da fonação de pacientes com diferentes patologias e que não fizeram parte desta pesquisa, posteriormente as fonoaudiólogas determinaram em conjunto a classificação das características morfológicas e do comportamento laríngeo, considerando a descrição a seguir (YAMASAKI, 2001):

- Características morfológicas: foi analisada a assimetria de aritenoides e pregas vocais, fazendo referência sobre a imagem especular de uma hemilaringe em ralação à outra. Para o arqueamento da porção membranosa, foi identificada a presença ou ausência da borda livre da porção membranosa da prega vocal, que assumiu uma posição arqueada. Também foi considerado o aumento e quantidade de volume 
das pregas vestibulares; quantidade de cobertura das aritenoides e epiglote em relação às pregas vocais.

- Características do comportamento laríngeo: foram consideradas as seguintes classificações:

- Classificação do fechamento glótico durante a fonação: a coaptação glótica corresponde ao modo que as pregas vocais aproximaram-se durante a fonação e serão analisadas três tipos de fendas ( $1^{\underline{a}}=$ fendas triangulares que se descreve como coaptação incompleta na parte posterior da glote de forma triangular com vértice voltado para região anterior; $2^{\underline{a}}=$ fendas fusiformes por coaptação incompleta que pode abarcar tudo ou só uma parte da região membranácea; $3^{\underline{a}}=$ fendas caracterizadas por formas diferentes).

- Classificação da constrição anteroposterior e mediana durante a fonação da vogal /i/: para a análise do comportamento do vestíbulo laríngeo foi considerada a presença ou ausência da constrição anteroposterior e mediana; a constrição anteroposterior, faz referência à distância das aritenoides e do pecíolo em relação á parede posterior da glote na respiração em relação à fonação e a constrição media é baseada na observação da configuração das pregas vestibulares durante a fonação.

- Assimetria laríngea: foi considero assimetria, como redução do movimento das pregas vocais durante a fonação.

4.3.1.2 Análise da deglutição a partir do exame de videoendoscopia As imagens foram analisadas por duas fonoaudiólogas com título mínimo de mestre e formação em disfagia orofaríngea. Para os resultados que pontuaram diferente número nas escalas da deglutição, foi realizado um consenso por meio de reanálises do exame da videoendoscopia pelas duas avaliadoras, ao mesmo tempo, até concordar no mesmo resultado. 


\section{Casuística e Métodos}

Foi aplicada a escala de penetração-aspiração (ROSENBEK et al., 1996), com o objetivo de medir a presença do alimento contrastado no vestíbulo da laringe, acima do plano das pregas vocais, e presença de alimento contrastado no plano da borda livre das pregas vocais e/ou abaixo delas (Quadro 1). A escala classifica a penetração/aspiração em oitos níveis, o nível 1 sem presença de alimentos contrastado na via aérea, e o nível 8 corresponde ao mais severo, o alimento contrastado ultrapassa a glote, resíduos na subglote sem resposta do paciente.

\begin{tabular}{|l|c|l|}
\hline \multicolumn{1}{|c|}{ Categoria } & Pontuação & \multicolumn{1}{|c|}{ Descrição } \\
\hline Sem penetração/aspiração & 1 & Contraste não entra em via aérea. \\
\hline \multirow{3}{*}{ Penetração } & 2 & $\begin{array}{l}\text { Contraste entra na via aérea, permanece acima das } \\
\text { pregas vocais, sem resíduo. }\end{array}$ \\
\cline { 2 - 3 } & 3 & $\begin{array}{l}\text { Contraste permanece acima das pregas vocais, com } \\
\text { permanência de resíduo visível. }\end{array}$ \\
\cline { 2 - 3 } & 4 & Contraste atinge pregas vocais, sem resíduo. \\
\hline \multirow{4}{*}{ Aspiração } & 5 & $\begin{array}{l}\text { Contraste atinge pregas vocais, com permanência de } \\
\text { resíduo visível. }\end{array}$ \\
\cline { 2 - 3 } & 7 & $\begin{array}{l}\text { Contraste passa o nível glótico, mas não há resíduo no } \\
\text { nível subglótico. }\end{array}$ \\
\cline { 2 - 3 } & 8 & $\begin{array}{l}\text { Contraste passa o nível glótico com resíduo no nível } \\
\text { subglótico, apesar da reação do paciente. }\end{array}$ \\
\cline { 2 - 3 } & & $\begin{array}{l}\text { Contraste passa a glote com resíduo na subglote, sem } \\
\text { reação do paciente. }\end{array}$ \\
\hline
\end{tabular}

Quadro 1. Escala de Penetração-Aspiração de Rosenbek et al. (1996)

Também foi determinado o nível de resíduos em valéculas e seios piriformes com o uso da escala Yale, que diferencia cinco níveis de resíduos (Quadros 2 e 3), sendo o nível I interpretado como nenhum tipo de resíduos, até o nível $\mathrm{V}$ interpretado como severo - cheio de resíduos até a rima glótica (NEUBAUER; RADEMAKER; LEDER, 2015). 
4 Casuística e Métodos

\begin{tabular}{|c|c|c|l|}
\hline Nível & Interpretação & Porcentagem & \multicolumn{1}{|c|}{ Categoria } \\
\hline I & Nenhum & $0 \%$ & Sem resíduo \\
\hline II & Traços & $1-5 \%$ & Cobertura de mucosa \\
\hline III & Leve & $5-25 \%$ & Ligamento epiglótico visível \\
\hline IV & Moderado & $25-50 \%$ & Ligamento epiglótico coberto \\
\hline V & Severo & $>50 \%$ & Cheio até a rima glótica \\
\hline
\end{tabular}

Quadro 2. Escala Yale do resíduo em valéculas

\begin{tabular}{|c|c|c|c|}
\hline Nível & Interpretação & Porcentagem & Categoria \\
\hline I & Nenhum & $0 \%$ & Sem resíduo \\
\hline II & Traços & $1-5 \%$ & Até um quarto \\
\hline III & Leve & $5-25 \%$ & Até a metade \\
\hline IV & Moderado & $25-50 \%$ & Cheio até a prega ariepiglótica \\
\hline V & Severo & $>50 \%$ & \\
\hline
\end{tabular}

Quadro 3. Escala Yale do resíduo em seios piriformes

Também foi aplicada a escala de resíduos em Faringe (Kelly et al., 2006), que permite identificar e classificar em 5 graus a presença de alimento contrastado em estruturas da orofaringe e laringofaringe. A interpretação varia de grau I, que se entende como nenhum (ausência de resíduos) até grau $\mathrm{V}$ (como severo), de acordo com o quadro 4.

\begin{tabular}{|c|c|}
\hline Graus & Escala de resíduos em faringe \\
\hline I & Nenhum \\
\hline II & Cobertura \\
\hline III & Leve \\
\hline IV & Moderado \\
\hline V & Severo \\
\hline
\end{tabular}

Quadro 4. Escala de resíduos em faringe proposta por Kelly et al. (2006) 


\title{
4.3.2 Análise dos dados:
}

\author{
Os resultados obtidos foram tabulados em banco de dados e submetidos à \\ análise estatística descritiva das variáveis estudadas, por meio da aplicação de \\ testes de associação e/ou correlação Mann-Whitey e Kruskal-Wallis por meio de \\ tabulação cruzada, considerando nível de significância de 5\%.
}

Para verificar a concordância interjuízes das escalas da deglutição e fonação foi utilizada a estatística Kappa. Quanto aos aspectos morfológicos da laringe, evidenciou-se valores de Kappa de 0,514 para o aumento das pregas vestibulares e 0,588 para quanto cobre a epiglote as pregas vocais, indicando concordância interjuízes moderada. Para o comportamento laríngeo fonatório (Tabela 3) os valores de Kappa foram 0,762 para a constrição anteroposterior pecíolo, 0,644 para constrição mediana e 0,662 para assimetria, interpretando-se como concordância substancial interjuízes.

Tabela 2. Valores médios de Kappa obtidos por meio da análise da concordância interjuízes para a morfologia da laringe.

\begin{tabular}{ccc}
\hline Morfologia & Kappa interjuízes & Interpretação \\
\hline Assimetria pregas vocais & 0,189 & Leve \\
& & \\
Assimetria aritenoides & 0,400 & Moderada \\
Aumento do volume das pregas vestibulares & 0,514 & Moderada \\
Quanto a epiglote cobre as pregas vocais & 0,588 & Considerável \\
\end{tabular}

Tabelas 3. Valores médios de Kappa obtidos por meio da análise da concordância interjuízes do comportamento da laríngeo fonatório.

\begin{tabular}{lcc}
\hline Comportamento laríngeo & $\begin{array}{c}\text { Kappa } \\
\text { interjuízes }\end{array}$ & Interpretação \\
\hline Fechamento glótico completo & 0,252 & Considerável
\end{tabular}




\begin{tabular}{ccc}
\hline Constrição anteroposterior pecíolo & 0,762 & Substancial \\
Constrição anteroposterior aritenoides & 0,517 & Moderada \\
Constrição mediana & 0,644 & Substancial \\
Assimetria & 0,662 & Substancial \\
\hline
\end{tabular}

Observou-se para todas as escalas da deglutição (Tabela 4) valor de Kappa de 0,929, indicando concordância perfeita interjuízes.

Tabela 4. Valores médios de Kappa obtidos por meio da análise da concordância interjuízes das escalas da deglutição nas diferentes consistências alimentares.

\begin{tabular}{ccc}
\hline Escalas & Kappa interjuízes & Interpretação \\
\hline Penetração-Aspiração & 0,929 & Perfeito \\
Resíduos Valécula & 0,929 & Perfeito \\
Resíduos Seios Piriformes & 0,929 & Perfeito \\
Resíduos Faringe & 0,929 & Peito \\
\hline
\end{tabular}





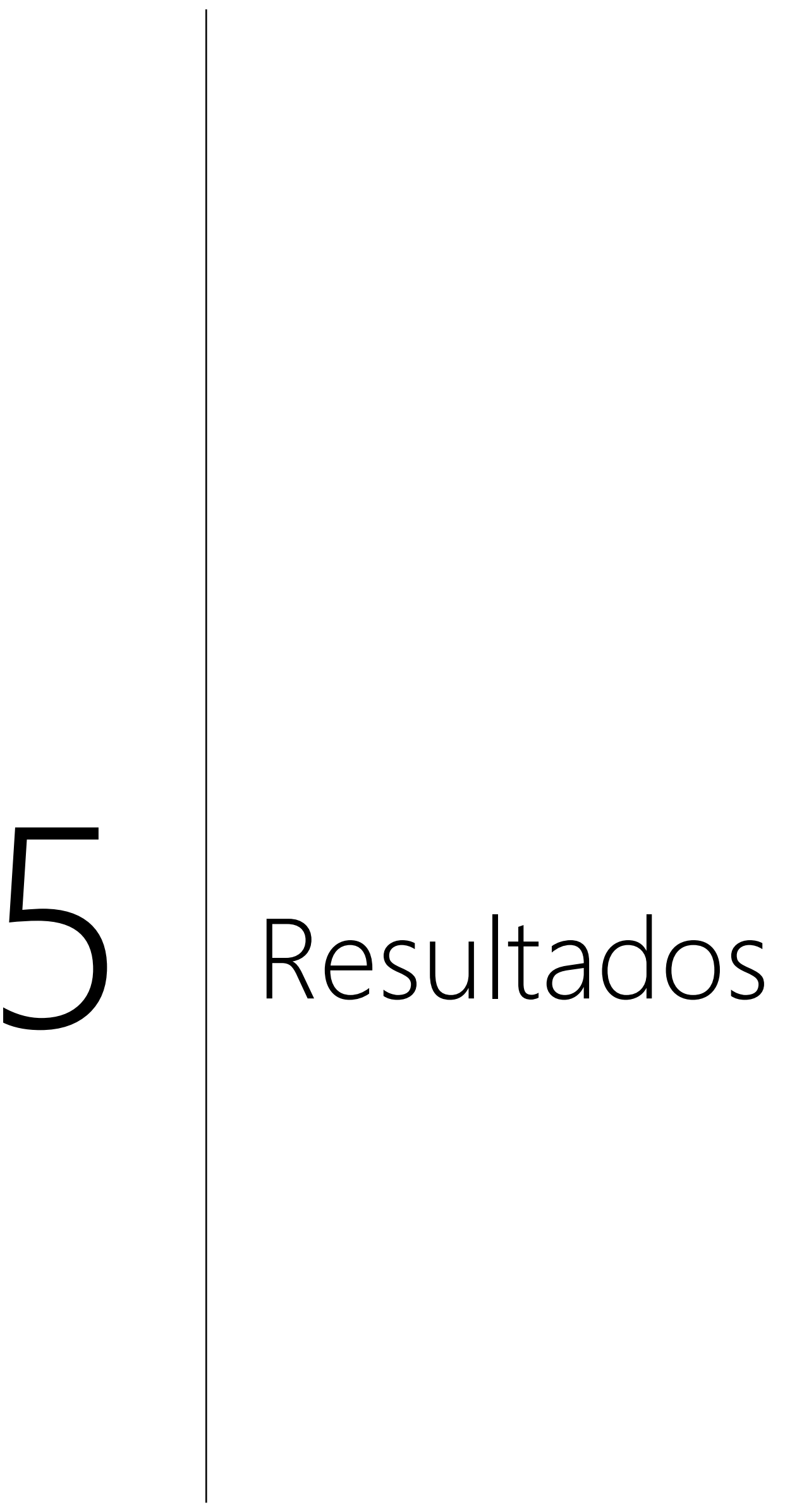






\section{Resultados}

\section{RESULTADOS}

\subsection{Videoendoscopia da fonação}

Por meio da videoendoscopia da fonação (VEF), onde foram solicitadas ao paciente respirar sem emitir algum som e posteriormente realizar e emissão da vogal "i” sustentada, foram obtidos os resultados apresentados nas Tabelas 5 e 6.

Tabela 5. Categorização morfológica da laringe em repouso, segundo os achados VEF.

\begin{tabular}{|c|c|c|c|c|c|c|}
\hline \multirow{3}{*}{ Pontuação } & \multicolumn{2}{|c|}{ Assimetria Laríngea } & \multirow{2}{*}{$\begin{array}{c}\text { Arqueamento da } \\
\text { porção } \\
\text { membranosa }\end{array}$} & \multirow{2}{*}{$\begin{array}{c}\text { Aumento de } \\
\text { volume das } \\
\text { Pregas } \\
\text { vestibulares }\end{array}$} & \multirow{2}{*}{$\begin{array}{c}\text { Quantidade } \\
\text { de aumento } \\
\text { de pregas } \\
\text { vestibulares }\end{array}$} & \multirow{2}{*}{$\begin{array}{c}\text { Quanto a epiglote } \\
\text { cobre as pregas } \\
\text { vocais }\end{array}$} \\
\hline & $\begin{array}{l}\text { Pregas } \\
\text { vocais }\end{array}$ & Aritenoides & & & & \\
\hline & $\mathrm{n}(\%)$ & $\mathrm{n}(\%)$ & $\overline{n(\%)}$ & $\mathrm{n}(\%)$ & n (\%) & n (\%) \\
\hline 0 & $19(79,2 \%)$ & $13(54,2 \%)$ & $2(8,3 \%)$ & $2(8,3 \%)$ & $2(8,3 \%)$ & $14(58,3 \%)$ \\
\hline 1 & $5(20,8 \%)$ & $11(45,8 \%)$ & $22(91,7 \%)$ & $22(91,7 \%)$ & $10(41,7 \%)$ & $9(37,5 \%)$ \\
\hline 2 & ----- & ----- & ----- & ----- & $4(16,7 \%)$ & $1(4,2 \%)$ \\
\hline 3 & ----- & ----- & ----- & ----- & $8(33,3 \%)$ & ------ \\
\hline
\end{tabular}

AL: (0) ausência/ (1) presença; APM: (0) ausência / (1) presença; AVPV: (0) ausência/ (1) presença ; QAPV: (0) nada/ (1) até a metade das pregas vocais/ (2) mais da metade das pregas vocais/ (3) cobertura total; QEPV: (0) nada/ (1) até a metade das pregas vocais/ (2) mais da metade das pregas vocais/ (3) cobertura total. 


\section{Resultados}

Tabela 6. Categorização do comportamento laríngeo durante a fonação da vogal "i".

\begin{tabular}{|c|c|c|c|c|c|}
\hline \multirow{3}{*}{ Pontuação } & \multirow{3}{*}{$\begin{array}{c}\begin{array}{c}\text { Fechamento } \\
\text { glótico } \\
\text { Completo }\end{array} \\
\mathbf{n}(\%)\end{array}$} & \multicolumn{2}{|c|}{ Constrição anteroposterior } & \multirow{2}{*}{$\begin{array}{c}\text { Constrição } \\
\text { Mediana }\end{array}$} & \multirow{2}{*}{ Assimetria } \\
\hline & & Pecíolo & Aritenoides & & \\
\hline & & $n(\%)$ & $n(\%)$ & $n(\%)$ & n (\%) \\
\hline 0 & $4(16,7 \%)$ & $10(41,7 \%)$ & $2(8,3 \%)$ & $8(33,3 \%)$ & $16(66,7 \%)$ \\
\hline 1 & $11(45,8 \%)$ & $13(\mathbf{5 4 , 2 \% )}$ & $21(87,5 \%)$ & $15(62,5 \%)$ & $7(29,2 \%)$ \\
\hline 2 & $9(37,5 \%)$ & $1(4,2 \%)$ & $1(4,2 \%)$ & $1(4,2 \%)$ & 1 (4,2\%) \\
\hline
\end{tabular}

Legenda: (0) ausência/ (1) presença/ (2) Não observável.

Com relação aos resultados evidenciou-se na morfologia que a maioria dos pacientes apresentou arqueamento na porção membranosa das pregas vocais $(91,7 \%)$ e aumento do volume das pregas vestibulares $(91,7 \%)$, seguido de ausência de assimetria (79,2\%). Quanto à função laríngea, observou-se constrição anteroposterior das aritenoides em $87,5 \%$ dos pacientes, seguido de presença de constrição mediana $(62,5 \%)$.

\subsection{Videoendoscopia da deglutição}

A videoendoscopia da deglutição (VED) foi avaliada considerando três consistências alimentares: pudim, sólido, líquido. Posteriormente foram aplicadas as escalas de penetração aspiração (ROSENBEK et al., 1996), resíduos em valécula e seios piriformes (YALE 2015), resíduos em faringe (Kelly et al., 2006). Os resultados obtidos estão descritos nas Tabelas 7 e 8. 
Tabela 7. Resultados da escala Pentração-Aspiração de acordo à VED

\begin{tabular}{|c|c|c|c|}
\hline \multirow{3}{*}{ Pontuação } & \multicolumn{3}{|c|}{ Consistências } \\
\hline & Líquido & Pudim & Solido \\
\hline & n (\%) & n (\%) & $n(\%)$ \\
\hline 1 & $17(70,8 \%)$ & $23(95,8 \%)$ & $22(91,7 \%)$ \\
\hline 2 & ------ & ------ & ------ \\
\hline 3 & $3(12,5 \%)$ & $1(4,2 \%)$ & ------ \\
\hline 5 & ------ & ------ & ------ \\
\hline 6 & ------ & ------ & ------ \\
\hline 7 & $1(4,2 \%)$ & ------ & ------ \\
\hline 8 & $2(8,3 \%)$ & ------ & ------ \\
\hline 9 & $1(4,2 \%)$ & ------ & $2(8,3 \%)$ \\
\hline
\end{tabular}

Legenda: (1) Contraste não entra em via aérea/ (3) Contraste permanece acima das pregas vocais, com permanência de resíduo visível/ (7) Contraste passa o nível glótico com resíduo no nível subglótico, apesar da reação do paciente/ (8) Contraste passa a glote com resíduo na subglote, sem reação do paciente/ (9) Consistência não aplicada.

Evidenciou-se para a escala de Penetração-Aspiração que 12,5\% dos casos apresentaram penetração e 8,3\% aspiração para a consistência líquida. A maioria dos pacientes para as três consistências pontuou "um", indicando que o contraste não entrou em via aérea. 


\section{Resultados}

Tabela 8. Achados da videoendoscopia da deglutição para resíduos em valécula, faringe e seios piriformes.

\section{Consistências}

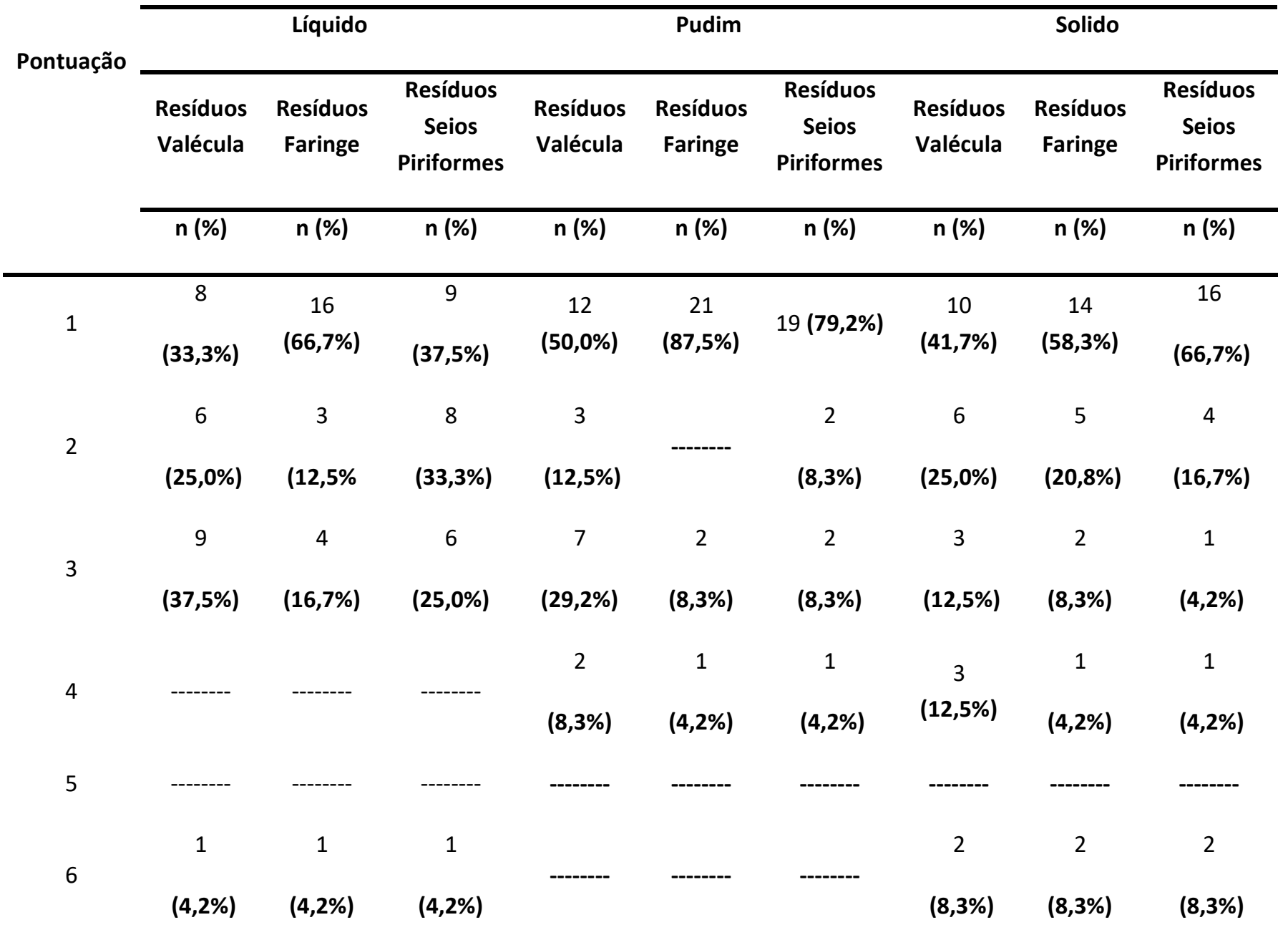

Legenda: RV: (1) sem resíduo/ (2) cobertura de mucosa/ (3) ligamento epiglótico visível/ (4) ligamento epiglótico coberto/ (6) não observável; RF: (1) nenhum/ (2) cobertura/ (3) leve(4) moderado/ (6) não observável; RSP (1) sem resíduo/ (2) Cobertura de mucosa/ (3) Até um quarto/ (4) Até a metade/ (6) não observável.

Para as escalas de resíduos, observou-se nas consistências do líquido, pudim e sólido, que a maioria dos pacientes pontuou "um", indicando ausência de resíduos nas estruturas. Especificamente para o líquido, o 33,3\% dos pacientes apresentaram resíduos em seios piriformes (pontuação dois) e para 29,2\% foi encontrado resíduos em valécula pudim (pontuação três). 


\subsection{Relações entre os resultados da avalição da deglutição e da voz}

Foi verificado se houve relação entre a morfologia e comportamento laríngeo com a escala de penetração-aspiração para as três consistências (líquido, pudim, sólido). Observou-se relação estatisticamente significante entre a penetração/aspiração de consistência líquida e a constrição anteroposterior de aritenoides $(p=0,047)$. Não se evidenciou nenhum tipo de relação significativa entre as demais variáveis estudadas, conforme apresentado nas tabelas 9 e 10 . 
5 Resultados

\begin{tabular}{|c|c|c|c|c|c|c|c|c|c|c|c|c|c|c|}
\hline & & \multicolumn{13}{|c|}{ Consistências } \\
\hline & & \multicolumn{6}{|c|}{ Líquido } & \multicolumn{6}{|c|}{ Pudim } & \multirow{2}{*}{$\begin{array}{l}\text { Sólido } \\
\text { Valor p }\end{array}$} \\
\hline & & $\begin{array}{c}\mathrm{N1} \\
\mathrm{n}(\%)\end{array}$ & $\begin{array}{c}\text { N3 } \\
n(\%)\end{array}$ & $\begin{array}{c}\text { N7 } \\
\mathrm{n}(\%)\end{array}$ & $\begin{array}{c}\text { N8 } \\
n(\%)\end{array}$ & $\begin{array}{l}\text { Total } \\
\mathrm{n}(\%)\end{array}$ & Valor $p$ & $\begin{array}{c}\text { N1 } \\
n(\%)\end{array}$ & $\begin{array}{c}\text { N3 } \\
\text { n (\%) }\end{array}$ & $\begin{array}{l}\text { Total } \\
\text { n (\%) }\end{array}$ & Valor $p$ & $\begin{array}{c}\mathrm{N1} \\
\mathrm{n}(\%)\end{array}$ & $\begin{array}{l}\text { Total } \\
\mathrm{n}(\%)\end{array}$ & \\
\hline Assimetria de PPVV & $\begin{array}{l}\text { Presente } \\
\text { Ausente }\end{array}$ & $\begin{array}{c}14 \\
(77.8 \%) \\
3 \\
(60 \%) \\
\end{array}$ & $\begin{array}{c}\mathbf{2} \\
(11.1 \%) \\
1 \\
(20 \%)\end{array}$ & $\begin{array}{c}1 \\
(5.6 \%) \\
0 \\
(0 \%)\end{array}$ & $\begin{array}{c}1 \\
(5.6 \%) \\
1 \\
(20 \%)\end{array}$ & $\begin{array}{c}18 \\
(100 \%) \\
5 \\
(100 \%)\end{array}$ & 0.538 & $\begin{array}{c}18 \\
(94.7 \%) \\
5 \\
(100 \%)\end{array}$ & $\begin{array}{c}1 \\
(5,3 \%) \\
0 \\
(0 \%)\end{array}$ & $\begin{array}{c}19 \\
(100 \% \\
5 \\
(100 \%) \\
\end{array}$ & 0.891 & $\begin{array}{c}17 \\
(100 \%) \\
5 \\
(100 \%)\end{array}$ & $\begin{array}{c}17 \\
(100 \%) \\
5 \\
(100 \%) \\
\end{array}$ & 1,000 \\
\hline Assimetria aritenoides & $\begin{array}{l}\text { Presente } \\
\text { Ausente }\end{array}$ & $\begin{array}{c}7 \\
(70 \%) \\
10 \\
(76,9 \%) \\
\end{array}$ & $\begin{array}{c}2 \\
(20 \%) \\
1 \\
(7,7 \%) \\
\end{array}$ & $\begin{array}{c}0 \\
(0 \%) \\
1 \\
(7,7 \%)\end{array}$ & $\begin{array}{c}1 \\
(10 \%) \\
1 \\
(7,7 \%)\end{array}$ & $\begin{array}{c}10 \\
(100 \%) \\
13 \\
(100 \%) \\
\end{array}$ & 0,832 & $\begin{array}{c}11 \\
(100 \%) \\
12 \\
(92,3 \%)\end{array}$ & $\begin{array}{c}0 \\
(0 \%) \\
1 \\
(4,2 \%) \\
\end{array}$ & $\begin{array}{c}11 \\
(100 \%) \\
13 \\
(100 \%)\end{array}$ & 0,776 & $\begin{array}{c}10 \\
(100 \%) \\
12 \\
(100 \%) \\
\end{array}$ & $\begin{array}{c}10 \\
(100 \%) \\
12 \\
(100 \%) \\
\end{array}$ & 1,000 \\
\hline $\begin{array}{c}\text { Arqueamento da porção } \\
\text { membranosa }\end{array}$ & $\begin{array}{l}\text { Presente } \\
\text { Ausente }\end{array}$ & $\begin{array}{c}16 \\
(76,2 \%) \\
1 \\
(50 \%) \\
\end{array}$ & $\begin{array}{c}3 \\
(14,3 \%) \\
0 \\
(0 \%) \\
\end{array}$ & $\begin{array}{c}0 \\
(0 \%) \\
1 \\
(50 \%)\end{array}$ & $\begin{array}{c}2 \\
(9,5 \%) \\
0 \\
(0 \%) \\
\end{array}$ & $\begin{array}{c}21 \\
(100 \%) \\
2 \\
(100 \%) \\
\end{array}$ & 0,569 & $\begin{array}{c}21 \\
(95,5 \%) \\
2 \\
(100 \%) \\
\end{array}$ & $\begin{array}{c}1 \\
(4,5 \%) \\
0 \\
(0 \%) \\
\end{array}$ & $\begin{array}{c}22 \\
(100 \%) \\
2 \\
(100 \%) \\
\end{array}$ & 1,000 & $\begin{array}{c}20 \\
(100 \%) \\
2 \\
(100 \%) \\
\end{array}$ & $\begin{array}{c}20 \\
(100 \%) \\
2 \\
(100 \%) \\
\end{array}$ & 1,000 \\
\hline $\begin{array}{c}\text { Aumento de volume das Pregas } \\
\text { vestibulares }\end{array}$ & $\begin{array}{l}\text { Presente } \\
\text { Ausente }\end{array}$ & $\begin{array}{c}16 \\
(76,2 \%) \\
1 \\
(50 \%) \\
\end{array}$ & $\begin{array}{c}2 \\
(9,5 \%) \\
1 \\
(50 \%) \\
\end{array}$ & $\begin{array}{c}1 \\
(4,8 \%) \\
0 \\
(0 \%)\end{array}$ & $\begin{array}{c}2 \\
(9,5 \%) \\
0 \\
(0 \%) \\
\end{array}$ & $\begin{array}{c}21 \\
(100 \%) \\
2 \\
(100 \%) \\
\end{array}$ & 0,711 & $\begin{array}{c}21 \\
(95,5 \%) \\
2 \\
(100 \%)\end{array}$ & $\begin{array}{c}1 \\
(4,5 \%) \\
0 \\
(0 \%) \\
\end{array}$ & $\begin{array}{c}22 \\
(100 \%) \\
2 \\
(100 \%) \\
\end{array}$ & 1,000 & $\begin{array}{c}20 \\
(100 \%) \\
2 \\
(100 \%) \\
\end{array}$ & $\begin{array}{c}20 \\
(100 \%) \\
2 \\
(100 \%) \\
\end{array}$ & 1,000 \\
\hline $\begin{array}{l}\text { Quantidade de aumento de } \\
\text { pregas vestibulares }\end{array}$ & $\begin{array}{l}\text { Metade } \\
\text { Mais da } \\
\text { Metade } \\
\text { Toda }\end{array}$ & $\begin{array}{c}1 \\
(50 \%) \\
7 \\
(70 \%) \\
3 \\
(100 \%) \\
6 \\
(75 \%) \\
\end{array}$ & $\begin{array}{c}1 \\
(50 \%) \\
1 \\
(10 \%) \\
0 \\
(0 \%) \\
1 \\
(12,5 \%) \\
\end{array}$ & $\begin{array}{c}0 \\
(0 \%) \\
1 \\
(10 \%) \\
0 \\
(0 \%) \\
0 \\
(0 \%) \\
\end{array}$ & $\begin{array}{c}0 \\
(0 \%) \\
1 \\
(10 \%) \\
0 \\
(0 \%) \\
1 \\
(12,5 \%) \\
\end{array}$ & $\begin{array}{c}2 \\
(100 \%) \\
10 \\
(100 \%) \\
3 \\
(100 \%) \\
8 \\
(100 \%) \\
\end{array}$ & 0,707 & $\begin{array}{c}2 \\
(100 \%) \\
10 \\
(100 \%) \\
4 \\
(100 \%) \\
7 \\
(87,5 \%) \\
\end{array}$ & $\begin{array}{c}0 \\
(0 \%) \\
0 \\
(0 \%) \\
0 \\
(0 \%) \\
1 \\
(12,5 \%) \\
\end{array}$ & $\begin{array}{c}2 \\
(100 \%) \\
10 \\
(100 \%) \\
4 \\
(100 \%) \\
8 \\
(100 \%) \\
\end{array}$ & 0,572 & $\begin{array}{c}2 \\
(100 \%) \\
9 \\
(100 \%) \\
4 \\
(100 \%) \\
7 \\
(100 \%) \\
\end{array}$ & $\begin{array}{c}2 \\
(0 \%) \\
9 \\
(100 \%) \\
4 \\
(100 \%) \\
7 \\
(100 \%) \\
\end{array}$ & 1,000 \\
\hline \multirow{3}{*}{$\begin{array}{l}\text { Quantidade de epiglote que } \\
\text { cobre as pregas vocais }\end{array}$} & Nada & $\begin{array}{c}1 \\
(50 \%) \\
7\end{array}$ & $\begin{array}{c}1 \\
(50 \%) \\
1\end{array}$ & $\begin{array}{c}0 \\
(0 \%) \\
1\end{array}$ & $\begin{array}{c}0 \\
(0 \%) \\
1\end{array}$ & $\begin{array}{c}2 \\
(100 \%) \\
10\end{array}$ & \multirow{3}{*}{0,389} & $\begin{array}{c}2 \\
(100 \%) \\
10\end{array}$ & $\begin{array}{c}0 \\
0 \\
(0 \%) \\
0\end{array}$ & $\begin{array}{c}2 \\
(100 \%) \\
10\end{array}$ & \multirow{3}{*}{0,700} & $\begin{array}{c}2 \\
(100 \%) \\
9\end{array}$ & $\begin{array}{c}2 \\
(100 \%) \\
9\end{array}$ & \multirow{3}{*}{1,000} \\
\hline & $\begin{array}{l}\text { Metade } \\
\text { Mais da } \\
\text { Metade }\end{array}$ & $\begin{array}{c}(70 \%) \\
3 \\
(100 \%)\end{array}$ & $\begin{array}{c}(10 \%) \\
0 \\
(0 \%)\end{array}$ & $\begin{array}{c}(10 \%) \\
0 \\
(0 \%)\end{array}$ & $\begin{array}{c}(10 \%) \\
0 \\
(0 \%)\end{array}$ & $\begin{array}{c}(100 \%) \\
3 \\
(100 \%)\end{array}$ & & $\begin{array}{c}(100 \%) \\
4 \\
(100 \%)\end{array}$ & $\begin{array}{c}(0 \%) \\
0 \\
(0 \%)\end{array}$ & $\begin{array}{c}(100 \%) \\
4 \\
(100 \%)\end{array}$ & & $\begin{array}{c}(100 \%) \\
4 \\
(100 \%)\end{array}$ & $\begin{array}{c}(100 \%) \\
4 \\
(100 \%)\end{array}$ & \\
\hline & Toda & $\begin{array}{c}6 \\
(75 \%)\end{array}$ & $\begin{array}{c}1 \\
(12,5 \%)\end{array}$ & $\begin{array}{c}0 \\
(0 \%)\end{array}$ & $\begin{array}{c}1 \\
(12,5 \%)\end{array}$ & $\begin{array}{c}8 \\
(100 \%)\end{array}$ & & $\begin{array}{c}7 \\
(87,5 \%)\end{array}$ & $\begin{array}{c}1 \\
(12,5 \%)\end{array}$ & $\begin{array}{c}8 \\
(100 \%)\end{array}$ & & $\begin{array}{c}7 \\
(100 \%)\end{array}$ & $\begin{array}{c}7 \\
(100 \%)\end{array}$ & \\
\hline
\end{tabular}

Legenda: (N1) Contraste não entra em via aérea/ (N3) Contraste permanece acima das pregas vocais, com permanência de resíduo visível/ (N7) Contraste passa o nível glótico com resíduo no nível subglótico, apesar da reação do paciente/ (N8) Contraste passa a glote com resíduo na subglote, sem reação do paciente. 
5 Resultados

Tabela 10. Relação entre comportamento fonatório laríngeo e a escala de Penetração-Aspiração.

\begin{tabular}{|c|c|c|c|c|c|c|c|c|c|c|c|c|c|c|}
\hline & & \multicolumn{13}{|c|}{ Consistências } \\
\hline & & \multicolumn{7}{|c|}{ Líquido } & \multicolumn{4}{|c|}{ Pudim } & \multicolumn{2}{|r|}{ Sólido } \\
\hline & & $\begin{array}{c}\mathrm{N} 1 \\
\mathrm{n}(\%)\end{array}$ & $\begin{array}{c}\text { N3 } \\
\text { n (\%) }\end{array}$ & $\begin{array}{c}\text { N7 } \\
\text { n (\%) }\end{array}$ & $\begin{array}{l}\text { N8 } \\
\text { n (\%) }\end{array}$ & $\begin{array}{l}\text { Total } \\
\text { n (\%) }\end{array}$ & $\begin{array}{l}\text { Valor } \\
\text { p }\end{array}$ & $\begin{array}{c}\text { N1 } \\
\text { n (\%) }\end{array}$ & $\begin{array}{c}\text { N3 } \\
\text { n (\%) }\end{array}$ & $\begin{array}{l}\text { Total } \\
\text { n (\%) }\end{array}$ & $\begin{array}{c}\text { Valor } \\
\mathbf{p}\end{array}$ & $\begin{array}{c}\text { N1 } \\
\text { n (\%) }\end{array}$ & $\begin{array}{l}\text { Total } \\
\text { n (\%) }\end{array}$ & $\begin{array}{l}\text { Valor } \\
\mathbf{P}\end{array}$ \\
\hline \multirow{2}{*}{$\begin{array}{l}\text { Fechamento glótico } \\
\text { Completo }\end{array}$} & Presente & $\begin{array}{c}8 \\
(72,9 \%)\end{array}$ & $\begin{array}{c}1 \\
(9,1 \%)\end{array}$ & $\begin{array}{c}1 \\
(9,1 \%)\end{array}$ & $\begin{array}{c}1 \\
(9,1 \%)\end{array}$ & $\begin{array}{c}11 \\
(100 \%)\end{array}$ & \multirow{2}{*}{0,949} & $\begin{array}{c}11 \\
(100 \%)\end{array}$ & $\begin{array}{c}0 \\
(0 \%)\end{array}$ & $\begin{array}{c}11 \\
(100 \%)\end{array}$ & \multirow{2}{*}{0,489} & $\begin{array}{c}10 \\
(100 \%)\end{array}$ & $\begin{array}{c}10 \\
(100 \%)\end{array}$ & \multirow{2}{*}{1,000} \\
\hline & Ausente & $\begin{array}{c}3 \\
(75 \%)\end{array}$ & $\begin{array}{c}0 \\
(0 \%)\end{array}$ & $\begin{array}{c}0 \\
(0 \%)\end{array}$ & $\begin{array}{c}1 \\
(25 \%)\end{array}$ & $\begin{array}{c}4 \\
(100 \%)\end{array}$ & & $\begin{array}{c}3 \\
(75 \%)\end{array}$ & $\begin{array}{c}1 \\
(25 \%)\end{array}$ & $\begin{array}{c}4 \\
(100 \%)\end{array}$ & & $\begin{array}{c}4 \\
(100 \%)\end{array}$ & $\begin{array}{c}4 \\
(100 \%)\end{array}$ & \\
\hline \multirow{2}{*}{$\begin{array}{l}\text { Constrição } \\
\text { anteroposterior pecíolo }\end{array}$} & Presente & $\begin{array}{c}9 \\
(69,2 \%)\end{array}$ & $\begin{array}{c}2 \\
(15,4 \%)\end{array}$ & $\begin{array}{c}1 \\
(7,7 \%)\end{array}$ & $\begin{array}{c}1 \\
(7,7 \%)\end{array}$ & $\begin{array}{c}13 \\
(100 \%)\end{array}$ & \multirow{2}{*}{0,693} & $\begin{array}{c}13 \\
(100 \%)\end{array}$ & $\begin{array}{c}0 \\
(0 \%)\end{array}$ & $\begin{array}{c}13 \\
(100 \%)\end{array}$ & \multirow{2}{*}{0,693} & $\begin{array}{c}11 \\
(100 \%)\end{array}$ & $\begin{array}{c}11 \\
(100 \%)\end{array}$ & \multirow{2}{*}{1,000} \\
\hline & Ausente & $\begin{array}{c}8 \\
(80 \%)\end{array}$ & $\begin{array}{c}1 \\
(10 \%)\end{array}$ & $\begin{array}{c}0 \\
(0 \%)\end{array}$ & $\begin{array}{c}1 \\
(10 \%)\end{array}$ & $\begin{array}{c}10 \\
(100 \%)\end{array}$ & & $\begin{array}{c}9 \\
(90 \%)\end{array}$ & $\begin{array}{c}1 \\
(10 \%)\end{array}$ & $\begin{array}{c}10 \\
(100 \%)\end{array}$ & & $\begin{array}{c}10 \\
(100 \%)\end{array}$ & $\begin{array}{c}10 \\
(100 \%)\end{array}$ & \\
\hline \multirow{2}{*}{$\begin{array}{c}\text { Constrição } \\
\text { anteroposterior } \\
\text { Aritenoides }\end{array}$} & Presente & $\begin{array}{c}17 \\
(81 \%)\end{array}$ & $\begin{array}{c}2 \\
(9,5 \%)\end{array}$ & $\begin{array}{c}1 \\
(4,8 \%)\end{array}$ & $\begin{array}{c}1 \\
(4,8 \%)\end{array}$ & $\begin{array}{c}21 \\
(100 \%)\end{array}$ & \multirow[b]{2}{*}{0,047} & $\begin{array}{c}20 \\
(95,2 \%)\end{array}$ & $\begin{array}{c}1 \\
(4,8 \%)\end{array}$ & $\begin{array}{c}21 \\
(100 \%)\end{array}$ & \multirow[b]{2}{*}{1,000} & $\begin{array}{c}20 \\
(100 \%)\end{array}$ & $\begin{array}{c}20 \\
(100 \%)\end{array}$ & \multirow[b]{2}{*}{1,000} \\
\hline & Ausente & $\begin{array}{c}0 \\
(0 \%)\end{array}$ & $\begin{array}{c}1 \\
(50 \%)\end{array}$ & $\begin{array}{c}0 \\
(0 \%)\end{array}$ & $\begin{array}{c}1 \\
(50 \%)\end{array}$ & $\begin{array}{c}2 \\
(100 \%)\end{array}$ & & $\begin{array}{c}2 \\
(100 \%)\end{array}$ & $\begin{array}{c}0 \\
(0 \%)\end{array}$ & $\begin{array}{c}2 \\
(100 \%)\end{array}$ & & $\begin{array}{c}1 \\
(100 \%)\end{array}$ & $\begin{array}{c}1 \\
(100 \%)\end{array}$ & \\
\hline \multirow{2}{*}{ Constrição Mediana } & Presente & $\begin{array}{c}12 \\
(80 \%)\end{array}$ & $\begin{array}{c}1 \\
(6,7 \%)\end{array}$ & $\begin{array}{c}1 \\
(6,7 \%)\end{array}$ & $\begin{array}{c}1 \\
(6,7 \%)\end{array}$ & $\begin{array}{c}15 \\
(100 \%)\end{array}$ & \multirow{2}{*}{0,548} & $\begin{array}{c}14 \\
(93,3 \%)\end{array}$ & $\begin{array}{c}1 \\
(6,7 \%)\end{array}$ & $\begin{array}{c}15 \\
(100 \%)\end{array}$ & \multirow{2}{*}{0,825} & $\begin{array}{c}15 \\
(100 \%)\end{array}$ & $\begin{array}{c}15 \\
(100 \%)\end{array}$ & \multirow{2}{*}{1,000} \\
\hline & Ausente & $\begin{array}{c}5 \\
(62,5 \%)\end{array}$ & $\begin{array}{c}2 \\
(25 \%)\end{array}$ & $\begin{array}{c}0 \\
(0 \%)\end{array}$ & $\begin{array}{c}1 \\
(12,5 \%)\end{array}$ & $\begin{array}{c}8 \\
(100 \%)\end{array}$ & & $\begin{array}{c}8 \\
(100 \%) \\
\end{array}$ & $\begin{array}{c}0 \\
(0 \%)\end{array}$ & $\begin{array}{c}8 \\
(100 \%)\end{array}$ & & $\begin{array}{c}6 \\
(100 \%)\end{array}$ & $\begin{array}{c}6 \\
(100 \%)\end{array}$ & \\
\hline \multirow{2}{*}{$\begin{array}{l}\text { Assimetria (redução do } \\
\text { movimento) }\end{array}$} & Presente & $\begin{array}{c}6 \\
(85,7 \%)\end{array}$ & $\begin{array}{c}0 \\
(0 \%)\end{array}$ & $\begin{array}{c}0 \\
(0 \%)\end{array}$ & $\begin{array}{c}1 \\
(14,3 \%)\end{array}$ & $\begin{array}{c}7 \\
(100 \%)\end{array}$ & \multirow{2}{*}{0,624} & $\begin{array}{c}7 \\
(85,7 \%)\end{array}$ & $\begin{array}{c}1 \\
(14,3 \%)\end{array}$ & $\begin{array}{c}8 \\
(100 \%)\end{array}$ & \multirow{2}{*}{0,24} & $\begin{array}{c}7 \\
(100 \%)\end{array}$ & $\begin{array}{c}7 \\
(100 \%)\end{array}$ & \multirow{2}{*}{1,000} \\
\hline & Ausente & $\begin{array}{c}11 \\
(68,8 \%)\end{array}$ & $\begin{array}{c}3 \\
(18,8 \%)\end{array}$ & $\begin{array}{c}1 \\
(6,3 \%)\end{array}$ & $\begin{array}{c}1 \\
(6,3 \%)\end{array}$ & $\begin{array}{c}16 \\
(100 \%)\end{array}$ & & $\begin{array}{c}16 \\
(100 \%)\end{array}$ & $\begin{array}{c}0 \\
(0 \%)\end{array}$ & $\begin{array}{c}16 \\
(100 \%)\end{array}$ & & $\begin{array}{c}14 \\
(100 \%)\end{array}$ & $\begin{array}{c}14 \\
(100 \%)\end{array}$ & \\
\hline
\end{tabular}

Legenda: (N1) Contraste não entra em via aérea/ (N3) Contraste permanece acima das pregas vocais, com permanência de resíduo visível/ (N7) Contraste passa o nível glótico com resíduo no nível subglótico, apesar da reação do paciente/ (N8) Contraste passa a glote com resíduo na subglote, sem reação do paciente.

As tabelas 11 e 12 mostram se houve relação entre a morfologia e comportamento laríngeo com a escala de resíduos em valécula. Evidenciou-se relação estatisticamente significante entre a consistência sólida e assimetria das pregas vocais $(p=0,009)$; relação da consistência pudim com quantidade de aumento das pregas vestibulares ( $p=0,040)$; e relação entre a consistência pudim com quanto a epiglote cobre as pregas vocais $(p=0,017)$. 
Tabela 11. Relação entre morfologia laríngea e a escala de resíduos em valéculas.

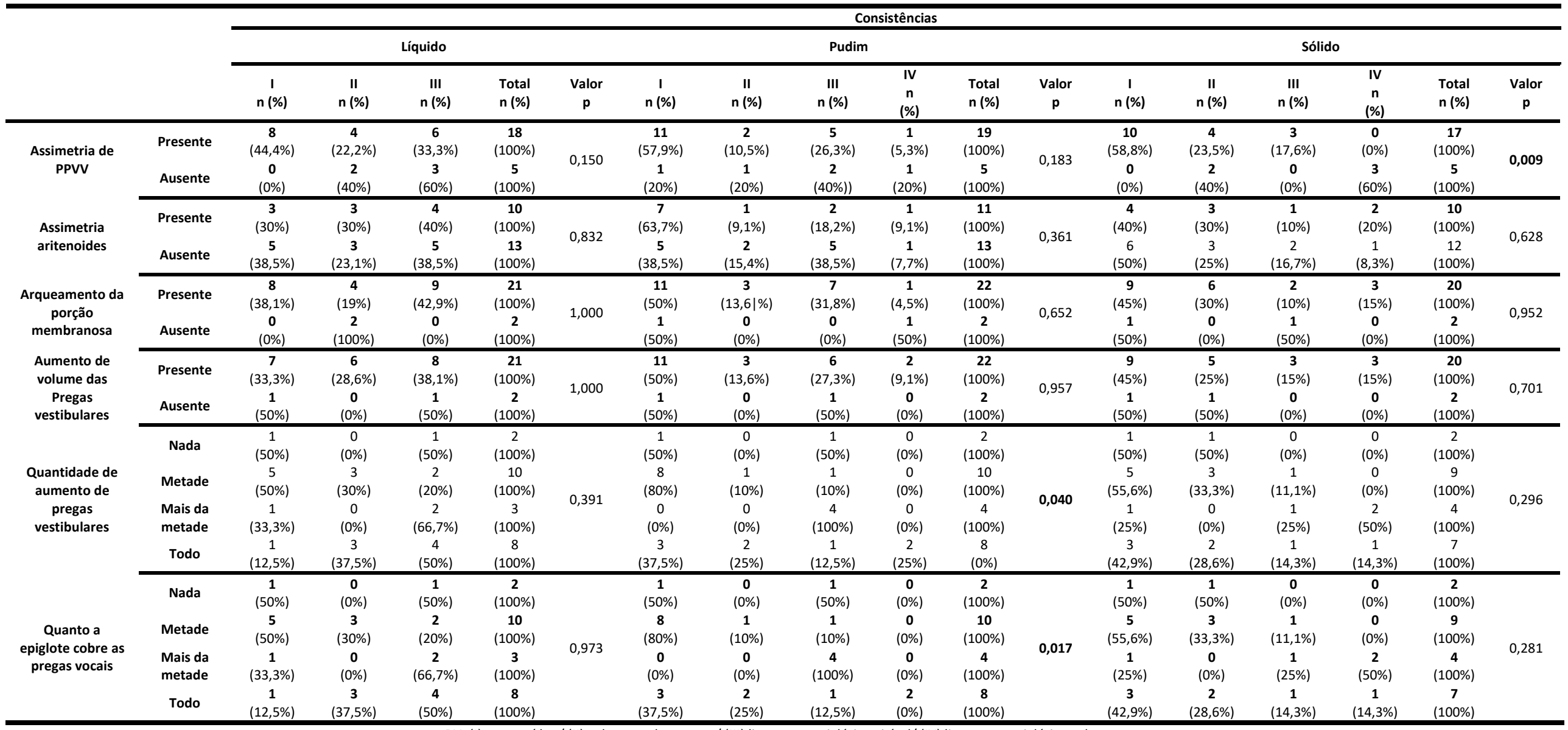


Tabela 12. Relação entre comportamento laríngeo fonatório e a escala de resíduos em valéculas.

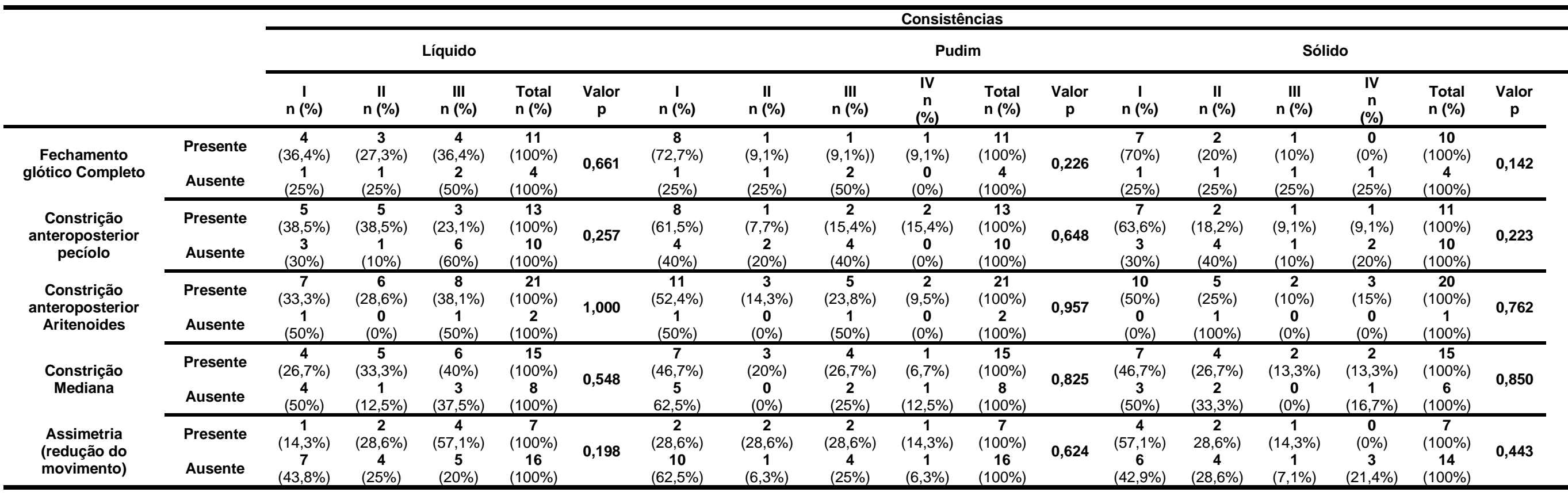

RV: (I) sem resíduo/ (II) cobertura de mucosa/ (III) ligamento epiglótico visível/ (IV) ligamento epiglótico coberto.

Por meio dos resultados apresentados nas tabelas 13 e 14 verificou-se que não houve relação estatisticamente significante entre a escala de resíduos de seios piriformes com a morfologia e o comportamento laríngeo. 
5 Resultados

Tabela 13. Relação entre morfologia laríngea e a escala de resíduos em seios piriformes.

\begin{tabular}{|c|c|c|c|c|c|c|c|c|c|c|c|c|c|c|c|c|c|c|}
\hline & & \multicolumn{16}{|c|}{ Consistências } & \multirow[b]{3}{*}{ Valor $\mathrm{P}$} \\
\hline & & \multicolumn{6}{|c|}{ Líquido } & \multicolumn{5}{|c|}{ Pudim } & \multicolumn{5}{|c|}{ Sólido } & \\
\hline & & $\begin{array}{c}1 \\
n(\%) \\
\end{array}$ & $\begin{array}{c}\text { II } \\
\text { n (\%) } \\
\end{array}$ & $\begin{array}{c}\text { III } \\
\text { n (\%) } \\
\end{array}$ & $\begin{array}{l}\text { Total } \\
\text { n (\%) } \\
\end{array}$ & $\begin{array}{c}\begin{array}{c}\text { Valor } \\
\mathbf{P}\end{array} \\
\end{array}$ & $\begin{array}{c}\mathrm{I} \\
\mathrm{n}(\%) \\
\end{array}$ & $\begin{array}{c}\text { II } \\
\text { n (\%) } \\
\end{array}$ & $\begin{array}{c}\text { III } \\
\text { n (\%) }\end{array}$ & $\begin{array}{c}\text { IV } \\
\text { n (\%) }\end{array}$ & $\begin{array}{l}\text { Total } \\
\mathbf{n}(\%) \\
\end{array}$ & $\begin{array}{c}\text { Valor } \\
\mathbf{P} \\
\end{array}$ & $\begin{array}{c}1 \\
\mathrm{n}(\%) \\
\end{array}$ & $\begin{array}{c}\text { II } \\
\text { n (\%) } \\
\end{array}$ & $\begin{array}{c}\text { III } \\
\text { n (\%) }\end{array}$ & $\begin{array}{c}\text { IV } \\
\text { N (\%) } \\
\end{array}$ & $\begin{array}{l}\text { Total } \\
\text { n (\%) } \\
\end{array}$ & \\
\hline \multirow{2}{*}{ Assimetria de PPVV } & Presente & $\begin{array}{c}2 \\
(40 \%)\end{array}$ & $\begin{array}{c}1 \\
(20 \%)\end{array}$ & $\begin{array}{c}2 \\
(40 \%)\end{array}$ & $\begin{array}{c}\mathbf{5} \\
(100 \%)\end{array}$ & \multirow{2}{*}{0,745} & $\begin{array}{c}3 \\
(60 \%)\end{array}$ & $\begin{array}{c}1 \\
(20 \%)\end{array}$ & $\begin{array}{c}\mathbf{0} \\
(0 \%)\end{array}$ & $\begin{array}{c}1 \\
(20 \%)\end{array}$ & $\begin{array}{c}\mathbf{5} \\
(100 \%)\end{array}$ & \multirow{2}{*}{0,406} & $\begin{array}{c}3 \\
(60 \%)\end{array}$ & $\begin{array}{c}1 \\
(20 \%)\end{array}$ & $\begin{array}{c}\mathbf{0} \\
(0 \%)\end{array}$ & $\begin{array}{c}1 \\
(20 \%)\end{array}$ & $\begin{array}{c}\mathbf{5} \\
(100 \%)\end{array}$ & \multirow{2}{*}{0,543} \\
\hline & Ausente & $\begin{array}{c}7 \\
(38,9 \%)\end{array}$ & $\begin{array}{c}7 \\
(38,9 \%)\end{array}$ & $\begin{array}{c}\mathbf{4} \\
(22,2 \%)\end{array}$ & $\begin{array}{c}18 \\
(100 \%)\end{array}$ & & $\begin{array}{c}16 \\
(84,2 \%)\end{array}$ & $\begin{array}{c}\mathbf{1} \\
(5,3 \%)\end{array}$ & $\begin{array}{c}\mathbf{2} \\
(10,5 \%)\end{array}$ & $\begin{array}{c}0 \\
(0 \%)\end{array}$ & $\begin{array}{c}19 \\
(100 \%)\end{array}$ & & $\begin{array}{c}13 \\
(76,5 \%)\end{array}$ & $\begin{array}{c}3 \\
(17,6 \%)\end{array}$ & $\begin{array}{c}1 \\
(5,9 \%)\end{array}$ & $\begin{array}{c}\mathbf{0} \\
(0 \%)\end{array}$ & $\begin{array}{c}17 \\
(100 \%)\end{array}$ & \\
\hline \multirow{2}{*}{ Assimetria aritenoides } & Presente & $\begin{array}{c}\mathbf{5} \\
(50 \%)\end{array}$ & $\begin{array}{c}2 \\
(20 \%)\end{array}$ & $\begin{array}{c}3 \\
(30 \%)\end{array}$ & $\begin{array}{c}10 \\
(100 \%)\end{array}$ & \multirow{2}{*}{0,693} & $\begin{array}{c}7 \\
(63,7 \%)\end{array}$ & $\begin{array}{c}2 \\
(18,2 \%)\end{array}$ & $\begin{array}{c}\mathbf{1} \\
(9,1 \%)\end{array}$ & $\begin{array}{c}\mathbf{1} \\
(9,1 \%)\end{array}$ & $\begin{array}{c}11 \\
(100 \%)\end{array}$ & \multirow{2}{*}{0,252} & $\begin{array}{c}7 \\
(70 \%)\end{array}$ & $\begin{array}{c}2 \\
(20 \%)\end{array}$ & $\begin{array}{c}0 \\
(0 \%)\end{array}$ & $\begin{array}{c}1 \\
(10 \%)\end{array}$ & $\begin{array}{c}10 \\
(100 \%)\end{array}$ & \multirow{2}{*}{0,821} \\
\hline & Ausente & $\begin{array}{c}\mathbf{4} \\
(30,8 \%)\end{array}$ & $\begin{array}{c}6 \\
(46,2 \%)\end{array}$ & $\begin{array}{c}\mathbf{3} \\
(23,1 \%)\end{array}$ & $\begin{array}{c}13 \\
(100 \%)\end{array}$ & & $\begin{array}{c}12 \\
(92,3 \%)\end{array}$ & $\begin{array}{c}0 \\
(0 \%)\end{array}$ & $\begin{array}{c}1 \\
(7,7 \%)\end{array}$ & $\begin{array}{c}\mathbf{0} \\
(0 \%)\end{array}$ & $\begin{array}{c}13 \\
(100 \%)\end{array}$ & & $\begin{array}{c}9 \\
(75 \%)\end{array}$ & $\begin{array}{c}2 \\
(16,7 \%)\end{array}$ & $\begin{array}{c}1 \\
(8,3 \%)\end{array}$ & $\begin{array}{c}0 \\
(0 \%)\end{array}$ & $\begin{array}{c}12 \\
(100 \%)\end{array}$ & \\
\hline \multirow{2}{*}{$\begin{array}{l}\text { Arqueamento da porção } \\
\text { membranosa }\end{array}$} & Presente & $\begin{array}{c}8 \\
(38,1 \%)\end{array}$ & $\begin{array}{c}7 \\
(33,3 \%)\end{array}$ & $\begin{array}{c}6 \\
(28,6 \%)\end{array}$ & $\begin{array}{l}21 \\
(100 \%)\end{array}$ & \multirow{2}{*}{0,569} & $\begin{array}{c}17 \\
(77,3 \%)\end{array}$ & $\begin{array}{c}2 \\
(9,1 \%)\end{array}$ & $\begin{array}{c}\mathbf{2} \\
(9,1 \%)\end{array}$ & $\begin{array}{c}1 \\
(4,5 \%)\end{array}$ & $\begin{array}{c}22 \\
(100 \%)\end{array}$ & \multirow{2}{*}{0,652} & $\begin{array}{c}15 \\
(75 \%)\end{array}$ & $\begin{array}{c}4 \\
(20 \%)\end{array}$ & $\begin{array}{c}0 \\
(0 \%)\end{array}$ & $\begin{array}{c}1 \\
(5 \%)\end{array}$ & $\begin{array}{c}20 \\
(100 \%)\end{array}$ & \multirow{2}{*}{0,485} \\
\hline & Ausente & $\begin{array}{c}1 \\
(50 \%)\end{array}$ & $\begin{array}{c}1 \\
(50 \%)\end{array}$ & $\begin{array}{c}0 \\
(0 \%)\end{array}$ & $\begin{array}{c}2 \\
(100 \%)\end{array}$ & & $\begin{array}{c}2 \\
(100 \%)\end{array}$ & $\begin{array}{c}0 \\
(0 \%)\end{array}$ & $\begin{array}{c}0 \\
(0 \%)\end{array}$ & $\begin{array}{c}0 \\
(0 \%)\end{array}$ & $\begin{array}{c}2 \\
(100 \%)\end{array}$ & & $\begin{array}{c}1 \\
(50 \%)\end{array}$ & $\begin{array}{c}0 \\
(0 \%)\end{array}$ & $\begin{array}{c}1 \\
(50 \%)\end{array}$ & $\begin{array}{c}0 \\
(0 \%)\end{array}$ & $\begin{array}{c}2 \\
(100 \%)\end{array}$ & \\
\hline \multirow{2}{*}{$\begin{array}{l}\text { Aumento de volume das Pregas } \\
\text { vestibulares }\end{array}$} & presente & $\begin{array}{c}8 \\
(38,1 \%)\end{array}$ & $\begin{array}{c}8 \\
(38,1 \%)\end{array}$ & $\begin{array}{c}\mathbf{5} \\
(23,8 \%)\end{array}$ & $\begin{array}{l}21 \\
(100 \%)\end{array}$ & \multirow{2}{*}{0,870} & $\begin{array}{c}18 \\
(81,8 \%)\end{array}$ & $\begin{array}{c}2 \\
(9,1 \%)\end{array}$ & $\begin{array}{c}1 \\
(4,5 \%)\end{array}$ & $\begin{array}{c}1 \\
(4,5 \%)\end{array}$ & $\begin{array}{c}22 \\
(100 \%)\end{array}$ & \multirow{2}{*}{0,464} & $\begin{array}{c}15 \\
(75 \%)\end{array}$ & $\begin{array}{c}3 \\
(15 \%)\end{array}$ & $\begin{array}{c}1 \\
(5 \%)\end{array}$ & $\begin{array}{c}1 \\
(5 \%)\end{array}$ & $\begin{array}{c}20 \\
(100 \%)\end{array}$ & \multirow{2}{*}{0,701} \\
\hline & Ausente & $\begin{array}{c}1 \\
(50 \%) \\
\end{array}$ & $\begin{array}{c}\mathbf{0} \\
(0 \%) \\
\end{array}$ & $\begin{array}{c}1 \\
(50 \%) \\
\end{array}$ & $\begin{array}{c}2 \\
(100 \%) \\
\end{array}$ & & $\begin{array}{c}1 \\
(50 \%) \\
\end{array}$ & $\begin{array}{c}0 \\
(0 \%)\end{array}$ & $\begin{array}{r}1 \\
(50 \%) \\
\end{array}$ & $\begin{array}{c}0 \\
(0 \%) \\
\end{array}$ & $\begin{array}{c}2 \\
(100 \%)\end{array}$ & & $\begin{array}{r}1 \\
(50 \%) \\
\end{array}$ & $\begin{array}{r}1 \\
(50 \%) \\
\end{array}$ & $\begin{array}{c}0 \\
(0 \%) \\
\end{array}$ & $\begin{array}{c}0 \\
(0 \%)\end{array}$ & $\begin{array}{c}2 \\
(100 \%)\end{array}$ & \\
\hline \multirow[t]{2}{*}{$\begin{array}{l}\text { Quantidade de aumento de } \\
\text { pregas vestibulares }\end{array}$} & $\begin{array}{c}\text { Nada } \\
\text { Metade } \\
\text { Mais da metade } \\
\text { Todo }\end{array}$ & $\begin{array}{c}1 \\
(50 \%) \\
4 \\
(40 \%) \\
2 \\
(66,7 \%) \\
2 \\
(25 \%) \\
\end{array}$ & $\begin{array}{c}0 \\
(0 \%) \\
4 \\
(40 \%) \\
0 \\
(0 \%) \\
4 \\
(50 \%) \\
\end{array}$ & $\begin{array}{c}1 \\
(50 \%) \\
2 \\
(20 \%) \\
1 \\
(33,3 \%) \\
2 \\
(25 \%) \\
\end{array}$ & $\begin{array}{c}2 \\
(100 \%) \\
10 \\
(100 \%) \\
3 \\
(100 \%) \\
8 \\
(100 \%) \\
\end{array}$ & 0,899 & $\begin{array}{c}1 \\
(50 \%) \\
7 \\
(70 \%) \\
3 \\
(75 \%) \\
8 \\
(100 \%) \\
\end{array}$ & $\begin{array}{c}0 \\
(0 \%) \\
2 \\
(20 \%) \\
0 \\
(0 \%) \\
0 \\
(0 \%) \\
\end{array}$ & $\begin{array}{c}1 \\
(50 \%) \\
1 \\
(10 \%) \\
0 \\
(0 \%) \\
0 \\
(0 \%) \\
\end{array}$ & $\begin{array}{c}0 \\
(0 \%) \\
0 \\
(0 \%) \\
1 \\
(25 \%) \\
0 \\
(0 \%) \\
\end{array}$ & $\begin{array}{c}2 \\
(100 \%) \\
10 \\
(100 \%) \\
4 \\
(100 \%) \\
8 \\
(100 \%) \\
\end{array}$ & 0,314 & $\begin{array}{c}1 \\
(50 \%) \\
6 \\
(66,7 \%) \\
3 \\
(75 \%) \\
6 \\
(85,7 \%) \\
\end{array}$ & $\begin{array}{c}1 \\
(50 \%) \\
2 \\
(22,2 \%) \\
0 \\
(0 \%) \\
1 \\
(14,3 \%) \\
\end{array}$ & $\begin{array}{c}0 \\
(0 \%) \\
1 \\
(11,1 \%) \\
0 \\
(0 \%) \\
0 \\
(0 \%) \\
\end{array}$ & $\begin{array}{c}0 \\
(0 \%) \\
0 \\
(0 \%) \\
1 \\
(25 \%) \\
0 \\
(0 \%) \\
\end{array}$ & $\begin{array}{c}2 \\
(100 \%) \\
9 \\
(100 \%) \\
4 \\
(100 \%) \\
7 \\
(100 \%) \\
\end{array}$ & 0,769 \\
\hline & Nada & $\begin{array}{c}1 \\
(50 \%)\end{array}$ & $\begin{array}{c}0 \\
(0 \%)\end{array}$ & $\begin{array}{c}1 \\
(50 \%)\end{array}$ & $\begin{array}{c}2 \\
(100 \%)\end{array}$ & \multirow{4}{*}{0,388} & $\begin{array}{c}1 \\
(50 \%)\end{array}$ & $\begin{array}{c}\mathbf{0} \\
(0 \%)\end{array}$ & $\begin{array}{c}1 \\
(50 \%)\end{array}$ & $\begin{array}{c}\mathbf{0} \\
(0 \%)\end{array}$ & $\begin{array}{c}2 \\
(100 \%)\end{array}$ & \multirow{4}{*}{0,119} & $\begin{array}{c}1 \\
(50 \%)\end{array}$ & $\begin{array}{c}1 \\
(50 \%)\end{array}$ & $\begin{array}{c}0 \\
(0 \%)\end{array}$ & $\begin{array}{c}\mathbf{0} \\
(0 \%)\end{array}$ & $\begin{array}{c}2 \\
(100 \%)\end{array}$ & \multirow{4}{*}{0,810} \\
\hline \multirow{3}{*}{$\begin{array}{l}\text { Quanto a epiglote cobre as } \\
\text { pregas vocais }\end{array}$} & Metade & $\begin{array}{c}\mathbf{4} \\
(40 \%)\end{array}$ & $\begin{array}{c}\mathbf{4} \\
(40 \%)\end{array}$ & $\begin{array}{c}2 \\
(20 \%)\end{array}$ & $\begin{array}{c}10 \\
(100 \%)\end{array}$ & & $\begin{array}{c}7 \\
(70 \%)\end{array}$ & $\begin{array}{c}2 \\
(20 \%)\end{array}$ & $\begin{array}{c}1 \\
(10 \%)\end{array}$ & $\begin{array}{c}\mathbf{0} \\
(0 \%)\end{array}$ & $\begin{array}{c}10 \\
(100 \%)\end{array}$ & & $\begin{array}{c}6 \\
(66,7 \%)\end{array}$ & $\begin{array}{c}\mathbf{2} \\
(22,2 \%)\end{array}$ & $\begin{array}{c}\mathbf{1} \\
(11,1 \%)\end{array}$ & $\begin{array}{c}\mathbf{0} \\
(0 \%)\end{array}$ & $\begin{array}{c}9 \\
(100 \%)\end{array}$ & \\
\hline & Mais da metade & $\begin{array}{c}2 \\
(66,7 \%)\end{array}$ & $\begin{array}{c}\mathbf{0} \\
(0 \%)\end{array}$ & $\begin{array}{c}1 \\
(33,3 \%)\end{array}$ & $\begin{array}{c}3 \\
(100 \%)\end{array}$ & & $\begin{array}{c}3 \\
(75 \%)\end{array}$ & $\begin{array}{c}0 \\
(0 \%)\end{array}$ & $\begin{array}{c}0 \\
(0 \%)\end{array}$ & $\begin{array}{c}1 \\
(25 \%)\end{array}$ & $\begin{array}{c}\mathbf{4} \\
(100 \%)\end{array}$ & & $\begin{array}{c}3 \\
(75 \%)\end{array}$ & $\begin{array}{c}0 \\
(0 \%)\end{array}$ & $\begin{array}{c}0 \\
(0 \%)\end{array}$ & $\begin{array}{c}1 \\
(25 \%)\end{array}$ & $\begin{array}{c}\mathbf{4} \\
(100 \%)\end{array}$ & \\
\hline & Todo & $\begin{array}{c}2 \\
(25 \%)\end{array}$ & $\begin{array}{c}4 \\
(50 \%)\end{array}$ & $\begin{array}{c}2 \\
(25 \%)\end{array}$ & $\begin{array}{c}8 \\
(100 \%)\end{array}$ & & $\begin{array}{c}8 \\
(100 \%)\end{array}$ & $\begin{array}{c}0 \\
(0 \%)\end{array}$ & $\begin{array}{c}0 \\
(0 \%)\end{array}$ & $\begin{array}{c}0 \\
(0 \%)\end{array}$ & $\begin{array}{c}8 \\
(100 \%)\end{array}$ & & $\begin{array}{c}6 \\
(85,7 \%)\end{array}$ & $\begin{array}{c}\mathbf{1} \\
(14,3 \%)\end{array}$ & $\begin{array}{c}0 \\
(0 \%)\end{array}$ & $\begin{array}{c}0 \\
(0 \%)\end{array}$ & $\begin{array}{c}7 \\
(100 \%)\end{array}$ & \\
\hline
\end{tabular}


Tabela 14. Relação entre comportamento laríngeo fonatório e a escala de resíduos em seios piriformes.

\begin{tabular}{|c|c|c|c|c|c|c|c|c|c|c|c|c|c|c|c|c|c|c|}
\hline & & \multicolumn{17}{|c|}{ Consistências } \\
\hline & & \multicolumn{6}{|c|}{ Líquido } & \multicolumn{5}{|c|}{ Pudim } & \multicolumn{6}{|c|}{ Sólido } \\
\hline & & $\begin{array}{c}1 \\
\mathrm{n}(\%) \\
\end{array}$ & $\begin{array}{c}\text { II } \\
\text { n (\%) }\end{array}$ & $\begin{array}{c}\text { III } \\
n(\%)\end{array}$ & $\begin{array}{l}\text { Total } \\
\text { n (\%) }\end{array}$ & Valor $\mathrm{p}$ & $\begin{array}{c}1 \\
n(\%)\end{array}$ & $\begin{array}{c}\text { II } \\
n(\%)\end{array}$ & $\begin{array}{c}\text { III } \\
\text { n (\%) }\end{array}$ & $\begin{array}{l}\text { IV } \\
\text { N (\%) }\end{array}$ & $\begin{array}{l}\text { Total } \\
\text { n (\%) }\end{array}$ & Valor $p$ & $\begin{array}{c}1 \\
n(\%)\end{array}$ & $\begin{array}{c}\text { II } \\
n(\%)\end{array}$ & $\begin{array}{c}\text { III } \\
\text { n (\%) }\end{array}$ & $\begin{array}{l}\text { IV } \\
\text { N (\%) }\end{array}$ & $\begin{array}{l}\text { Total } \\
\mathbf{n}(\%)\end{array}$ & Valor $p$ \\
\hline $\begin{array}{l}\text { Fechamento glótico } \\
\text { Completo }\end{array}$ & $\begin{array}{l}\text { Presente } \\
\text { Ausente }\end{array}$ & $\begin{array}{c}\mathbf{5} \\
(45,5 \%) \\
\mathbf{1} \\
(25 \%) \\
\end{array}$ & $\begin{array}{c}\mathbf{4} \\
(36,4 \%) \\
\mathbf{1} \\
(25 \%) \\
\end{array}$ & $\begin{array}{c}2 \\
(18,2 \%) \\
2 \\
(50 \%) \\
\end{array}$ & $\begin{array}{c}11 \\
(100 \%) \\
\mathbf{4} \\
(100 \%) \\
\end{array}$ & 0,343 & $\begin{array}{c}\mathbf{9} \\
(81,8 \%) \\
\mathbf{3} \\
(75 \%) \\
\end{array}$ & $\begin{array}{c}0 \\
(0 \%) \\
1 \\
(25 \%) \\
\end{array}$ & $\begin{array}{c}2 \\
(18,2 \%) \\
0 \\
(0 \%) \\
\end{array}$ & --- & $\begin{array}{c}11 \\
(100 \%) \\
\mathbf{4} \\
(100 \%) \\
\end{array}$ & 0,949 & $\begin{array}{c}8 \\
(80 \%) \\
2 \\
(50 \%) \\
\end{array}$ & $\begin{array}{c}1 \\
(10 \%) \\
2 \\
(50 \%) \\
\end{array}$ & $\begin{array}{c}1 \\
(10 \%) \\
0 \\
(0 \%) \\
\end{array}$ & --- & $\begin{array}{c}10 \\
(100 \%) \\
\mathbf{4} \\
(100 \%) \\
\end{array}$ & 0,539 \\
\hline $\begin{array}{l}\text { Constrição anteroposterior } \\
\text { pecíolo }\end{array}$ & $\begin{array}{l}\text { Presente } \\
\text { Ausente }\end{array}$ & $\begin{array}{c}\mathbf{5} \\
(38,5 \%) \\
\mathbf{4} \\
(40 \%)\end{array}$ & $\begin{array}{c}7 \\
(53,8 \%) \\
1 \\
(10 \%) \\
\end{array}$ & $\begin{array}{c}\mathbf{1} \\
(7,7 \%) \\
\mathbf{5} \\
(50 \%) \\
\end{array}$ & $\begin{array}{c}13 \\
(100 \%) \\
10 \\
(100 \%)\end{array}$ & 0,343 & $\begin{array}{c}11 \\
(84,6 \%) \\
7 \\
(70 \%) \\
\end{array}$ & $\begin{array}{c}1 \\
(7,7 \%) \\
1 \\
(10 \%)\end{array}$ & $\begin{array}{c}\mathbf{1} \\
(7,7 \%) \\
\mathbf{1} \\
(10 \%) \\
\end{array}$ & $\begin{array}{c}\mathbf{0} \\
(0 \%) \\
1 \\
(10 \%)\end{array}$ & $\begin{array}{c}13 \\
(100 \%) \\
10 \\
(100 \%)\end{array}$ & 0,522 & $\begin{array}{c}10 \\
(90,9 \%) \\
5 \\
(50 \%)\end{array}$ & $\begin{array}{c}0 \\
(0 \%) \\
4 \\
(40 \%)\end{array}$ & $\begin{array}{c}1 \\
(9,1 \%) \\
0 \\
(0 \%) \\
\end{array}$ & $\begin{array}{c}\mathbf{0} \\
(0 \%) \\
1 \\
(10 \%)\end{array}$ & $\begin{array}{c}11 \\
(100 \%) \\
10 \\
(100 \%)\end{array}$ & 0,152 \\
\hline $\begin{array}{c}\text { Constrição anteroposterior } \\
\text { Aritenoides }\end{array}$ & $\begin{array}{l}\text { Presente } \\
\text { Ausente }\end{array}$ & $\begin{array}{c}\mathbf{9} \\
(42,9 \%) \\
\mathbf{0} \\
(0 \%)\end{array}$ & $\begin{array}{c}7 \\
(33,3 \%) \\
1 \\
(50 \%)\end{array}$ & $\begin{array}{c}5 \\
(23,8 \%) \\
1 \\
(50 \%)\end{array}$ & $\begin{array}{c}\mathbf{2 1} \\
(100 \%) \\
2 \\
(100 \%)\end{array}$ & 0,332 & $\begin{array}{c}17 \\
(81 \%) \\
1 \\
(50 \%)\end{array}$ & $\begin{array}{c}\mathbf{2} \\
(9,5 \%) \\
\mathbf{0} \\
(0 \%)\end{array}$ & $\begin{array}{c}1 \\
(4,8 \%) \\
1 \\
(50 \%)\end{array}$ & $\begin{array}{c}1 \\
(4,8 \%) \\
0 \\
(0 \%)\end{array}$ & $\begin{array}{c}\mathbf{2 1} \\
(100 \%) \\
\mathbf{2} \\
(100 \%)\end{array}$ & 0,506 & $\begin{array}{c}15 \\
(75 \%) \\
0 \\
(0 \%)\end{array}$ & $\begin{array}{c}3 \\
(15 \%) \\
1 \\
(100 \%)\end{array}$ & $\begin{array}{c}1 \\
(5 \%) \\
0 \\
(0 \%)\end{array}$ & $\begin{array}{c}1 \\
(5 \%) \\
0 \\
(0 \%) \\
\end{array}$ & $\begin{array}{c}\mathbf{2 0} \\
(100 \%) \\
1 \\
(100 \%)\end{array}$ & 0,381 \\
\hline Constrição Mediana & $\begin{array}{l}\text { presente } \\
\text { Ausente }\end{array}$ & $\begin{array}{c}\mathbf{5} \\
(33,3 \%) \\
\mathbf{4} \\
(50 \%)\end{array}$ & $\begin{array}{c}\mathbf{6} \\
(40 \%) \\
\mathbf{2} \\
(25 \%)\end{array}$ & $\begin{array}{c}\mathbf{4} \\
(26,7 \%) \\
\mathbf{2} \\
(25 \%)\end{array}$ & $\begin{array}{c}15 \\
(100 \%) \\
8 \\
(100 \%)\end{array}$ & 0,636 & $\begin{array}{c}13 \\
(86,7 \%) \\
5 \\
(62,5 \%)\end{array}$ & $\begin{array}{c}\mathbf{1} \\
(6,7 \%) \\
\mathbf{1} \\
(12,5 \%)\end{array}$ & $\begin{array}{c}0 \\
(0 \%) \\
2 \\
(25 \%) \\
\end{array}$ & $\begin{array}{c}1 \\
(6,7 \%) \\
0 \\
(0 \%)\end{array}$ & $\begin{array}{c}15 \\
(100 \%) \\
8 \\
(100 \%)\end{array}$ & 0,392 & $\begin{array}{c}11 \\
(73,3 \%) \\
4 \\
(66,7 \%)\end{array}$ & $\begin{array}{c}\mathbf{2} \\
(13,3 \%) \\
\mathbf{2} \\
(33,3 \%)\end{array}$ & $\begin{array}{c}1 \\
(6,7 \%) \\
0 \\
(0 \%)\end{array}$ & $\begin{array}{c}1 \\
(6,7 \%) \\
0 \\
(0 \%)\end{array}$ & $\begin{array}{c}15 \\
(100 \%) \\
6 \\
(100 \%)\end{array}$ & 0,970 \\
\hline $\begin{array}{c}\text { Assimetria (redução do } \\
\text { movimento }\end{array}$ & $\begin{array}{l}\text { Presente } \\
\text { Ausente }\end{array}$ & $\begin{array}{c}\mathbf{3} \\
(42,9 \%) \\
\mathbf{6} \\
(37,5 \%)\end{array}$ & $\begin{array}{c}0 \\
(0 \%) \\
8 \\
(50 \%) \\
\end{array}$ & $\begin{array}{c}\mathbf{4} \\
(57,1 \%) \\
\mathbf{2} \\
(12,5 \%)\end{array}$ & $\begin{array}{c}7 \\
(100 \%) \\
16 \\
(100 \%)\end{array}$ & 0,413 & $\begin{array}{c}6 \\
(85,7 \%) \\
12 \\
(75 \%) \\
\end{array}$ & $\begin{array}{c}1 \\
(14,3 \%) \\
\mathbf{1} \\
(6,3 \%)\end{array}$ & $\begin{array}{c}\mathbf{0} \\
(0 \%) \\
\mathbf{2} \\
(12,5 \%)\end{array}$ & $\begin{array}{c}0 \\
(0 \%) \\
1 \\
(6,3 \%)\end{array}$ & $\begin{array}{c}7 \\
(100 \%) \\
16 \\
(100 \%)\end{array}$ & 0,624 & $\begin{array}{c}\mathbf{5} \\
(71,4 \%) \\
10 \\
(71,4 \%)\end{array}$ & $\begin{array}{c}\mathbf{2} \\
(28,6 \%) \\
\mathbf{2} \\
(14,3 \%)\end{array}$ & $\begin{array}{c}\mathbf{0} \\
(0 \%) \\
\mathbf{1} \\
(7,1 \%)\end{array}$ & $\begin{array}{c}0 \\
(0 \%) \\
1 \\
(7,1 \%)\end{array}$ & $\begin{array}{c}7 \\
(100 \%) \\
14 \\
(100 \%)\end{array}$ & 0,913 \\
\hline
\end{tabular}

Verificou-se relação significativa entre a escala de resíduos em faringe com a morfologia laríngea (tabelas 15 e 16), especificamente na consistência solida com assimetria das pregas vocais $(p=0,048)$ e entre a consistência pudim e quantidade de aumento das pregas vestibulares $(p=0,020)$. Quanto ao comportamento laríngeo, evidenciou-se relação significativa entre a consistência líquida com constrição anteroposterior de aritenóides ( $p=0,032)$. 
5 Resultados

Tabela 15. Relação entre morfologia laríngea e a escala de resíduos em faringe

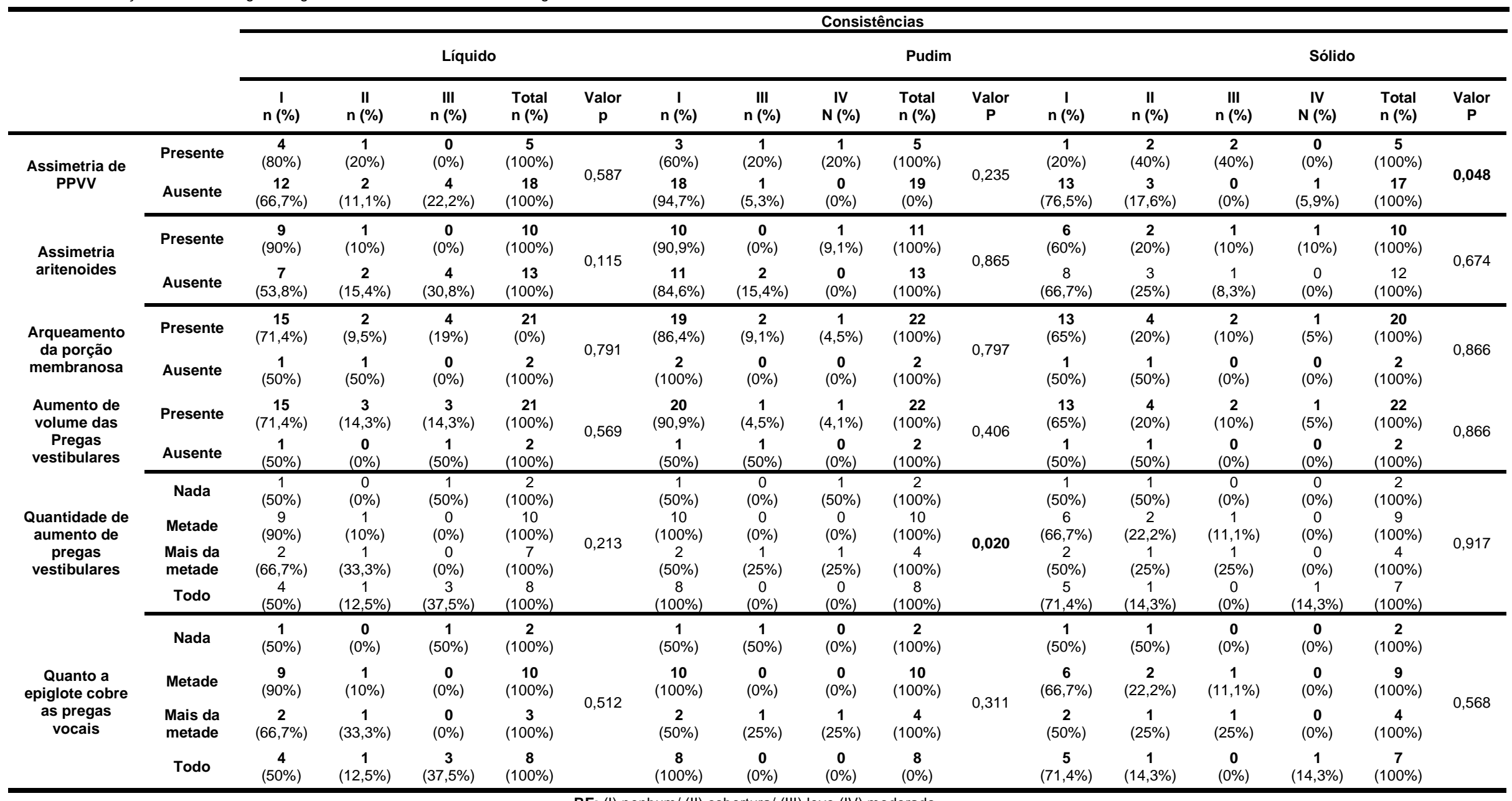


5 Resultados

Tabela 16. Relação entre comportamento fonatório laríngeo e a escala de resíduos em faringe.

\begin{tabular}{|c|c|c|c|c|c|c|c|c|c|c|c|c|c|c|c|c|c|}
\hline & & \multicolumn{16}{|c|}{ Consistências } \\
\hline & & \multicolumn{6}{|c|}{ Líquido } & \multicolumn{4}{|c|}{ Pudim } & \multicolumn{6}{|c|}{ Sólido } \\
\hline & & n (\%) & $\begin{array}{c}\text { II } \\
\text { n (\%) }\end{array}$ & $\begin{array}{c}\text { III } \\
\text { n (\%) }\end{array}$ & $\begin{array}{l}\text { Total } \\
\text { n (\%) }\end{array}$ & $\begin{array}{c}\text { Valor } \\
\mathbf{p}\end{array}$ & n 1 (\%) & $\begin{array}{c}\text { III } \\
\text { n (\%) }\end{array}$ & $\begin{array}{c}\text { IV } \\
\text { N (\%) }\end{array}$ & $\begin{array}{l}\text { Total } \\
\text { n (\%) }\end{array}$ & $\begin{array}{c}\text { Valor } \\
\mathbf{p}\end{array}$ & n 1 (\%) & $\begin{array}{c}\text { II } \\
\text { n (\%) }\end{array}$ & $\begin{array}{c}\text { III } \\
\text { n (\%) }\end{array}$ & $\begin{array}{c}\text { IV } \\
\text { N (\%) }\end{array}$ & $\begin{array}{l}\text { Total } \\
\text { n (\%) }\end{array}$ & $\begin{array}{c}\text { Valor } \\
\mathbf{p}\end{array}$ \\
\hline \multirow{2}{*}{$\begin{array}{l}\text { Fechamento } \\
\text { glótico Completo }\end{array}$} & Presente & $\begin{array}{c}\mathbf{8} \\
(72,7 \%)\end{array}$ & $\begin{array}{c}\mathbf{1} \\
(9,1 \%)\end{array}$ & $\begin{array}{c}\mathbf{2} \\
(18,2 \%)\end{array}$ & $\begin{array}{c}11 \\
(100 \%)\end{array}$ & \multirow{2}{*}{0,489} & $\begin{array}{c}10 \\
(90,9 \%)\end{array}$ & $\begin{array}{c}\mathbf{1} \\
(9,1 \%)\end{array}$ & -- & $\begin{array}{c}\mathbf{1 1} \\
(100 \%)\end{array}$ & \multirow{2}{*}{0,661} & $\begin{array}{c}6 \\
(60 \%)\end{array}$ & $\begin{array}{c}3 \\
(30 \%)\end{array}$ & $\begin{array}{c}0 \\
(0 \%)\end{array}$ & $\begin{array}{c}\mathbf{1} \\
(10 \%)\end{array}$ & $\begin{array}{c}\mathbf{1 0} \\
(100 \%)\end{array}$ & \multirow{2}{*}{0,635} \\
\hline & Ausente & $\begin{array}{c}\mathbf{4} \\
(100 \%) \\
\end{array}$ & $\begin{array}{c}\mathbf{0} \\
(0 \%) \\
\end{array}$ & $\begin{array}{c}\mathbf{0} \\
(0 \%) \\
\end{array}$ & $\begin{array}{c}4 \\
(100 \%) \\
\end{array}$ & & $\begin{array}{c}3 \\
(75 \%) \\
\end{array}$ & $\begin{array}{c}1 \\
(25 \%) \\
\end{array}$ & -- & $\begin{array}{c}4 \\
(0 \%) \\
\end{array}$ & & $\begin{array}{c}2 \\
(50 \%) \\
\end{array}$ & $\begin{array}{c}0 \\
(0 \%) \\
\end{array}$ & $\begin{array}{c}2 \\
(50 \%) \\
\end{array}$ & $\begin{array}{c}0 \\
(0 \%) \\
\end{array}$ & $\begin{array}{c}4 \\
(100 \%) \\
\end{array}$ & \\
\hline \multirow{2}{*}{$\begin{array}{c}\text { Constrição } \\
\text { anteroposterior } \\
\text { pecíolo }\end{array}$} & Presente & $\begin{array}{c}\mathbf{8} \\
(61,5 \%)\end{array}$ & $\begin{array}{c}2 \\
(15,4 \%)\end{array}$ & $\begin{array}{c}\mathbf{3} \\
(23,1 \%)\end{array}$ & $\begin{array}{c}13 \\
(100 \%)\end{array}$ & \multirow{2}{*}{0,446} & $\begin{array}{c}13 \\
(100 \%)\end{array}$ & $\begin{array}{c}\mathbf{0} \\
(0 \%)\end{array}$ & $\begin{array}{c}0 \\
(0 \%)\end{array}$ & $\begin{array}{c}13 \\
(100 \%)\end{array}$ & \multirow{2}{*}{0,232} & $\begin{array}{c}8 \\
(72,7 \%)\end{array}$ & $\begin{array}{c}\mathbf{2} \\
(18,2 \%)\end{array}$ & $\begin{array}{c}0 \\
(0 \%)\end{array}$ & $\begin{array}{c}\mathbf{1} \\
(9,1 \%)\end{array}$ & $\begin{array}{c}11 \\
(100 \%)\end{array}$ & \multirow{2}{*}{0,426} \\
\hline & Ausente & $\begin{array}{c}8 \\
(80 \%) \\
\end{array}$ & $\begin{array}{c}1 \\
(10 \%) \\
\end{array}$ & $\begin{array}{c}1 \\
(10 \%) \\
\end{array}$ & $\begin{array}{c}10 \\
(100 \%) \\
\end{array}$ & & $\begin{array}{c}7 \\
(70 \%) \\
\end{array}$ & $\begin{array}{c}2 \\
(20 \%) \\
\end{array}$ & $\begin{array}{c}\mathbf{1} \\
(10 \%) \\
\end{array}$ & $\begin{array}{c}10 \\
(100 \%) \\
\end{array}$ & & $\begin{array}{c}5 \\
(50 \%) \\
\end{array}$ & $\begin{array}{c}3 \\
(30 \%) \\
\end{array}$ & $\begin{array}{c}2 \\
(20 \%) \\
\end{array}$ & $\begin{array}{c}0 \\
(0 \%) \\
\end{array}$ & $\begin{array}{c}10 \\
(100 \%)\end{array}$ & \\
\hline \multirow{2}{*}{$\begin{array}{l}\text { Constrição } \\
\text { anteroposterior } \\
\text { Aritenoides }\end{array}$} & Presente & $\begin{array}{c}16 \\
(76,2 \%)\end{array}$ & $\begin{array}{c}3 \\
(14,3 \%)\end{array}$ & $\begin{array}{c}\mathbf{2} \\
(9,5 \%)\end{array}$ & $\begin{array}{c}21 \\
(100 \%)\end{array}$ & \multirow{2}{*}{0,032} & $\begin{array}{c}19 \\
(90,5 \%)\end{array}$ & $\begin{array}{c}\mathbf{1} \\
(4,8 \%)\end{array}$ & $\begin{array}{c}\mathbf{1} \\
(4,8 \%)\end{array}$ & $\begin{array}{c}21 \\
(100 \%)\end{array}$ & \multirow{2}{*}{0,443} & $\begin{array}{c}13 \\
(65 \%)\end{array}$ & $\begin{array}{c}\mathbf{4} \\
(20 \%)\end{array}$ & $\begin{array}{c}\mathbf{2} \\
(10 \%)\end{array}$ & $\begin{array}{c}1 \\
(5 \%)\end{array}$ & $\begin{array}{c}20 \\
(100 \%)\end{array}$ & \multirow{2}{*}{0,571} \\
\hline & Ausente & $\begin{array}{c}\mathbf{0} \\
(0 \%)\end{array}$ & $\begin{array}{c}0 \\
(0 \%)\end{array}$ & $\begin{array}{c}\mathbf{2} \\
(100 \%)\end{array}$ & $\begin{array}{c}2 \\
(100 \%)\end{array}$ & & $\begin{array}{c}1 \\
(50 \%)\end{array}$ & $\begin{array}{c}1 \\
(50 \%)\end{array}$ & $\begin{array}{c}0 \\
(0 \%)\end{array}$ & $\begin{array}{c}2 \\
(100 \%)\end{array}$ & & $\begin{array}{c}\mathbf{0} \\
(0 \%)\end{array}$ & $\begin{array}{c}\mathbf{1} \\
(100 \%)\end{array}$ & $\begin{array}{c}0 \\
(0 \%)\end{array}$ & $\begin{array}{c}0 \\
(0 \%)\end{array}$ & $\begin{array}{c}\mathbf{1} \\
(100 \%)\end{array}$ & \\
\hline \multirow{2}{*}{$\begin{array}{c}\text { Constrição } \\
\text { Mediana }\end{array}$} & Presente & $\begin{array}{c}10 \\
(66,7 \%)\end{array}$ & $\begin{array}{c}3 \\
(20 \%)\end{array}$ & $\begin{array}{c}\mathbf{2} \\
(13,3 \%)\end{array}$ & $\begin{array}{c}15 \\
(100 \%)\end{array}$ & \multirow{2}{*}{0,925} & $\begin{array}{c}14 \\
(93,3 \%)\end{array}$ & $\begin{array}{c}\mathbf{0} \\
(0 \%)\end{array}$ & $\begin{array}{c}\mathbf{1} \\
(6,7 \%)\end{array}$ & $\begin{array}{c}15 \\
(100 \%)\end{array}$ & \multirow{2}{*}{0,548} & $\begin{array}{c}9 \\
(60 \%)\end{array}$ & $\begin{array}{c}\mathbf{4} \\
(26,7 \%)\end{array}$ & $\begin{array}{c}\mathbf{1} \\
(6,7 \%)\end{array}$ & $\begin{array}{c}\mathbf{1} \\
(6,7 \%)\end{array}$ & $\begin{array}{c}15 \\
(100 \%)\end{array}$ & \multirow{2}{*}{0,850} \\
\hline & Ausente & $\begin{array}{c}6 \\
(75 \%) \\
\end{array}$ & $\begin{array}{c}0 \\
(0 \%) \\
\end{array}$ & $\begin{array}{c}\mathbf{2} \\
(25 \%) \\
\end{array}$ & $\begin{array}{c}8 \\
(100 \%) \\
\end{array}$ & & $\begin{array}{c}6 \\
(75 \%) \\
\end{array}$ & $\begin{array}{c}2 \\
(25 \%) \\
\end{array}$ & $\begin{array}{c}0 \\
(0 \%) \\
\end{array}$ & $\begin{array}{c}8 \\
(100 \%) \\
\end{array}$ & & $\begin{array}{c}4 \\
(66,7 \%) \\
\end{array}$ & $\begin{array}{c}1 \\
(16,7 \%) \\
\end{array}$ & $\begin{array}{c}\mathbf{1} \\
(16,7 \%) \\
\end{array}$ & $\begin{array}{c}0 \\
(0 \%) \\
\end{array}$ & $\begin{array}{c}6 \\
(100 \%) \\
\end{array}$ & \\
\hline \multirow{2}{*}{$\begin{array}{l}\text { Assimetria } \\
\text { (redução do } \\
\text { movimento) }\end{array}$} & Presente & $\begin{array}{c}6 \\
(85,7 \%)\end{array}$ & $\begin{array}{c}0 \\
(0 \%)\end{array}$ & $\begin{array}{c}\mathbf{1} \\
(14,7 \%)\end{array}$ & $\begin{array}{c}7 \\
(100 \%)\end{array}$ & \multirow{2}{*}{0,452} & $\begin{array}{c}7 \\
(100 \%)\end{array}$ & $\begin{array}{c}0 \\
(0 \%)\end{array}$ & $\begin{array}{c}0 \\
(0 \%)\end{array}$ & $\begin{array}{c}7 \\
(100 \%)\end{array}$ & \multirow{2}{*}{0,492} & $\begin{array}{c}\mathbf{5} \\
(71,4 \%)\end{array}$ & $\begin{array}{c}\mathbf{1} \\
(14,3 \%)\end{array}$ & $\begin{array}{c}\mathbf{1} \\
(14,3 \%)\end{array}$ & $\begin{array}{c}0 \\
(0 \%)\end{array}$ & $\begin{array}{c}7 \\
(100 \%)\end{array}$ & \multirow{2}{*}{0,636} \\
\hline & Ausente & $\begin{array}{c}10 \\
(62,5 \%)\end{array}$ & $\begin{array}{c}3 \\
(18,8 \%)\end{array}$ & $\begin{array}{c}3 \\
(18,8 \%)\end{array}$ & $\begin{array}{c}16 \\
(100 \%)\end{array}$ & & $\begin{array}{c}13 \\
(81,3 \%)\end{array}$ & $\begin{array}{c}\mathbf{2} \\
(12,5 \%)\end{array}$ & $\begin{array}{c}\mathbf{1} \\
(6,3 \%)\end{array}$ & $\begin{array}{c}16 \\
(100 \%)\end{array}$ & & $\begin{array}{c}8 \\
(57,1 \%)\end{array}$ & $\begin{array}{c}\mathbf{4} \\
(28,6 \%)\end{array}$ & $\begin{array}{c}\mathbf{1} \\
(7,1 \%)\end{array}$ & $\begin{array}{c}0 \\
(0 \%)\end{array}$ & $\begin{array}{c}14 \\
(100 \%)\end{array}$ & \\
\hline
\end{tabular}

RF: (I) nenhum/ (II) cobertura/ (III) leve (IV) moderado. 



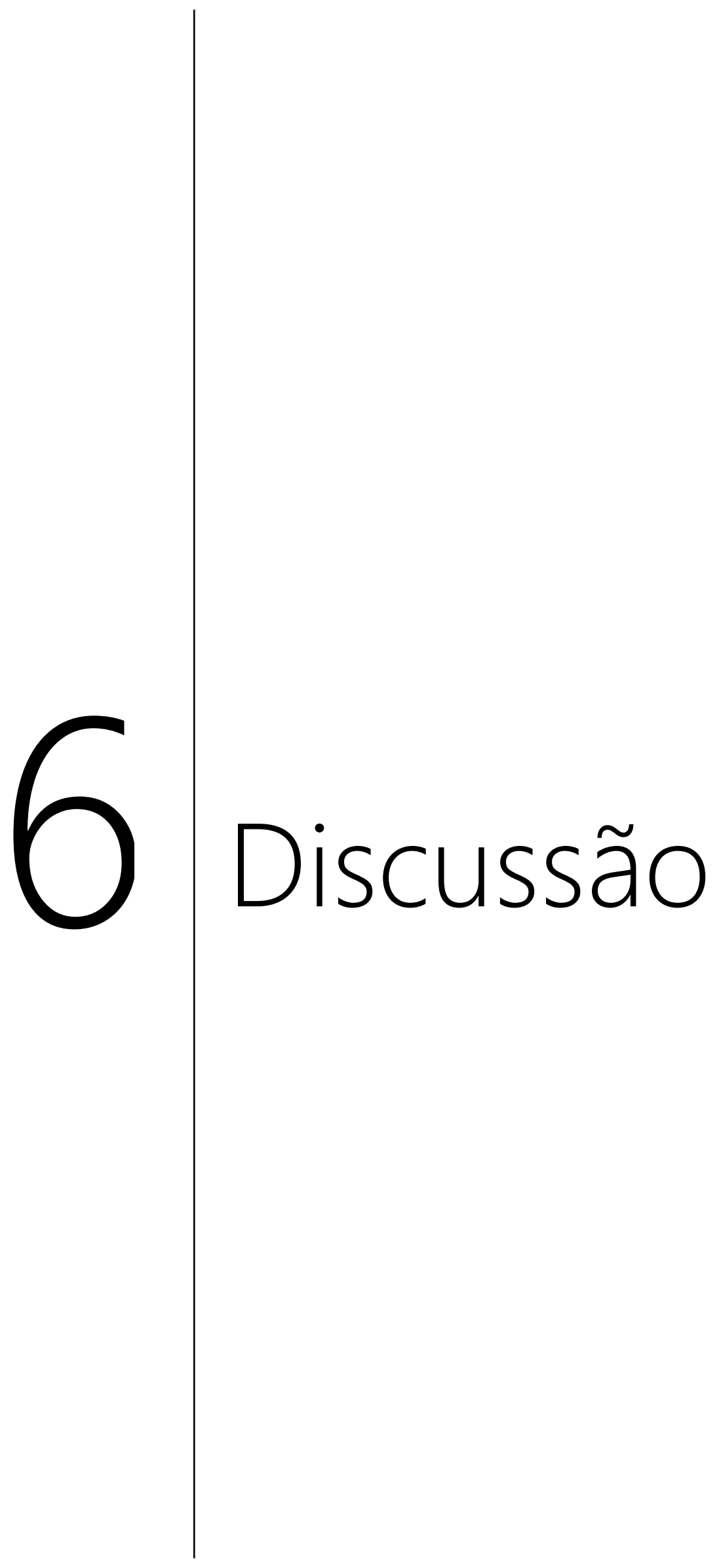






\section{Discussão}

\section{Discussão}

A incidência de pessoas com acontecimento de acidente vascular cerebral, é cada dia mais frequente, trazendo como consequência alterações motoras, de fala e da linguagem. Tendo em vista que os idosos compreendem a população mais afetada, se faz necessária a procura de novos conhecimentos que permitam entender as alterações nas áreas de voz e deglutição, que favoreçam os processos de avaliação e intervenção e contribuir na qualidade de vida durante o processo de envelhecimento. Sendo assim, o presente estudo pesquisou as possíveis relações entre as características morfológicas e do comportamento fonatório laríngeo com as características do processo da deglutição em idosos com acidente vascular cerebral tardio.

A partir dos resultados obtidos foi verificado que a maioria dos pacientes apresentou arqueamento da porção membranosa das pregas vocais, aumento de cobertura das pregas vestibulares até metade das pregas vocais, seguido de assimetria das aritenoides e pregas vocais. Um estudo similar em idosos saudáveis, arqueamento das pregas vocais $(23,8 \%)$ e saliência nos processos vocais (29,5\%) (PONTES; BRASOLOTTO; BEHLAU, 2005). Posteriormente, Siquera (2013), estudando idosos saudáveis, verificou aumento de volume das pregas vestibulares. Especificamente em pacientes idosos com AVC, um estudo (CAMPOS, 2013) evidenciou presença de assimetria laríngea e arqueamento bilateral das pregas vocais, concordando com os resultados achados nesta pesquisa. De acordo com a literatura, tais características morfológicas acontecem devido ao envelhecimento, evidenciando-se na anatomia e fisiologia laríngea, presença do enfraquecimento muscular, como atrofia do musculo tiroaritenóideo, calcificação das cartilagens hialinas, diminuição de fibras elásticas das pregas vocais e prejuízos no controle neuromuscular na laringe, acarretando, assim, presença de disfonia nos idosos (YAMAMOTO et al., 2003; MARTINS et al., 2015).

No comportamento laríngeo durante a fonação observou-se, para a maioria dos pacientes, fechamento glótico completo, constrição anteroposterior das aritenoides e do pecíolo, constrição mediana e assimetria no comportamento laríngeo (redução do movimento das pregas vocais). Estudo semelhante (SIQUERA, 2013) identificou em idosos saudáveis fendas fusiformes e constrições supraglóticas, associadas ao aumento da tensão durante a produção da voz, como medidas compensatórias à presença de fechamento glótico incompleto causado pelo envelhecimento (GAMA et al., 2009). Outros estudos realizados com nasoendoscopia da fonação em idosos acometidos por AVC, mostraram alteração no controle motor laríngeo com diminuição da mobilidade das pregas vocais, presença constrição supraglóticas anteroposterior e constrição mediana (ALTMAN et al., 2007; CAMPOS, 2013; FERNANDES, 2014). Uma explicação da causa da redução do movimento das pregas vocais segundo Yamamoto et al., (2003), se deve à redução das fibras elásticas e do ácido hialurônico, que causam rigidez, alterando assim, as propriedades viscoelásticas das pregas vocais. Referente ao fechamento 
glótico encontrou-se nesta pesquisa que, na maioria dos casos, houve fechamento glótico completo, diferente no que a literatura aborda, sobre as funções e características laríngeas em pacientes com alterações neurológicas (GOMES, 2004; MARRARA, 2010). O fechamento glótico completo pode ser justificado pelo tipo população, já que as análises da casuística foram realizadas em estado tardio do AVC, tendo em vista que, segundo Altman et al. (2007), as alterações laríngeas por etiologias neurológicas como o AVC podem ter recuperação após estados agudos.

Por meio dos resultados da nasoendoscopia da deglutição foi verificado ausência de contraste em via aérea (escala de Penetração-Aspiração nível 1) na avaliação das consistências líquida para a maioria dos participantes $(70,8 \%)$, pudim $(95,8 \%)$ e sólida $(91,7 \%)$, sendo que apenas um paciente apresentou penetração da consistência pudim. Viana et al. (2010) avaliaram a deglutição em pacientes com AVC, com método cintilográfico, observando-se presença de sinais de aspiração de pastoso em $15 \%$ dos pacientes avaliados (4/26) e, mesmo que os resultados sejam diferentes, evidenciou-se que a incidência de sinais se aspiração foi baixa em ambas pesquisas. No caso dos idosos, a presença de Penetração-Aspiração pode indicar falhas no mecanismo de proteção devido a alterações na sensibilidade laríngea; possivelmente à diminuição das fibras mielinizadas do nervo laríngeo superior, causando atrasos no desencadeamento do reflexo da deglutição, gerando uma incoordenação nos processos da deglutição, facilitando entrada do alimento nas vias aéreas inferiores e aumentando o risco de infeções pulmonares nos idosos (MORTELLITI et al., 1990; ROBBINS, 1996; LOGEMANN et al., 2000)

Para explicar a baixa ocorrência de Pentração-Aspiração evidenciada nos pacientes desta pesquisa, deve-se entender primeiramente que o sistema nervoso central do ato da deglutição envolve além dos centros do tronco encefálico, uma extensa rede supramedular de deglutição, bem como as áreas pré-motoras e o córtex sensório motor primário. Essa rede responde de forma plástica e compensatória a doenças do sistema nervoso central e periférico causantes de distúrbios da deglutição (LEOPO, DANIELS, 2010; WERNECK, DZIEWAS, 2013). Essa plasticidade cerebral foi evidenciada em pesquisas que relataram a recuperação da disfagia pós AVC, só dois pacientes de 406 a pós três meses do AVC continuaram com alteração da deglutição (PACIARONI et al., 2004) e apenas um paciente de 357 a pós 6 meses do AVC continuou com disfagia (BAER, 1993). Portanto, a baixa ocorrência de PentraçãoAspiração, evidenciada nesta pesquisa, pode ser explicada pelo fato de que o tempo em média do acontecimento nos pacientes foi de 62 meses após o AVC e, segundo a literatura, a melhora da disfagia pode acontecer entre 15 a 69 dias, dependo da plasticidade neuronal e grau de severidade do AVC (HUSSAIN et al., 1996).

Para a escala de resíduos em faringe observou-se que $41,7 \%$ dos pacientes apresentaram presença para a consistência sólida, 29,2\% na deglutição de líquido e 12,5\% para 


\section{Discussão}

pudim. Pesquisa em pacientes com lesões neurológicas (EISENHUBER et al., 2002) encontrou resíduos em faringe com níveis leves na maioria dos pacientes após deglutição com a consistência líquida, seguida da consistência pastosa, sendo que tais achados discordam com os resultados da presente pesquisa, já que resíduos da consistência sólida foi a de maior presença se comparada com as consistências líquida e pudim, com níveis moderados de resíduos em faringe para as três consistências. De acordo com Chen et al. (1990), a presença de resíduos na faringe pode estar relacionada à paresia faríngea, peristaltismo faríngeo reduzido ou paralisia faríngea unilateral, considerando-se tais achados como sinais de alteração no processo da deglutição, podendo estar presentes em pacientes acometidos por qualquer tipo de AVC, independente da topografia da lesão.

Encontrou-se, na escala de valéculas, para a maioria dos pacientes, presença de resíduos das consistências líquida (62,5\%), pudim (50\%) e sólido (50\%); enquanto para a escala de seios piriformes houve presença de resíduos somente para a consistência liquida (58,3\%). Andrade et al. (2009) identificaram os mesmos resultados para as escalas de valéculas e seios piriformes, com presença de resíduos para a consistência pastosa $(48,6 \%)$ e líquido $(43,2 \%)$ a pós deglutição em pacientes diagnosticados com disfagia neurogênica. Nos idosos, como o avanço do tempo, surgem diversas alterações anatômicas e neurofisiológicas que levam a uma modificação do processo de deglutição sem resultar em uma doença de risco. Uma justificativa para a presença de resíduos na fase faríngea observados nesta pesquisa pode ser devido à diminuição da abertura do esfíncter esofágico superior, causada pela redução da elasticidade, além da alteração da pressão da língua e da tração dos músculos hilaríngeos, contribuindo à diminuição da velocidade na elevação da laringe, causando comprometimento da passagem do bolo pela faringe. Essas alterações são verificadas com frequência nos idosos, atribuídas ao processo do envelhecimento (TRACY et al, 1989 LOGEMANN et al., 2000; MILOSAVLJEVIC et al.,2013 NISHIKUBO et al.,2014).

Em ralação aos pacientes após o AVC, Vilardell et al. (2017) identificaram que a presença de resíduos pode estar relacionada a um grave atraso na reconfiguração da faríngea, baixa força de propulsão em língua, além das características intrínsecas da viscosidade do bolo, uma vez que a maior viscosidade pode resultar no aumento de resíduos na região faríngea e ao mesmo tempo, em menor invasão de alimento em vias aeras, contribuindo para a proteção.

A análise estatística permitiu demostrar, no presente estudo, correlações significantes entre as características laríngeas e da deglutição. Uma das relações foi entre a escala de Penetração-Aspiração (consistência líquida) e a constrição anteroposterior das aritenoides. Uma explicação para este achado poderia ser à ação compensatória das estruturas da fonação como mecanismo de proteção das vias aéreas ao identificar uma alteração no processo da deglutição, evitando a entrada do alimento em vias aéreas inferiores (GOMES, 2004). Nos casos contrários, onde se evidenciou presença de penetração-aspiração, com ausência de alteração laríngea, 
pode ser justificado ao que o líquido é uma consistência fina, descendo rápido pela orofaringe, sem aderência nas paredes e sem causar alguma medida compensatória laríngea, somando-se a uma possível alteração na sensibilidade laríngea (ANDRADE et al., 2009; CHAN, 2012).

Outra correlação verificada neste estudo foi entre os baixos escores na escala de resíduos em valéculas e a presença de assimetria das pregas vocais no repouso, a quantidade de aumento das pregas vestibulares e a quantidade de cobertura da epiglote em relação com as pregas vocais. Tais condições, segundo Campos (2013), são causadas por auxílio na função esfintérica do processo de deglutição, que depende da musculatura constritora da faringe, juntamente com o movimento posterior da língua, explicando, assim, o escores baixos de resíduos em valécula. Outra explicação seria pelo envelhecimento, que resulta em modificações e/ou alterações na morfologia laríngea como a incompetência glótica e assimetria das pregas vocais; essas alterações podem ser explicadas como medidas compensatórias laríngeas na tentativa de reajustar ações correspondentes à fonação e deglutição (PONTES et al., 2005; CAMPOS 2013), além da influência de fatores hormonais, metabólicas e/ ou neurológicos, comumente evidenciado nos idosos (BOONE, BAYLE E KOOPMAN, 1982; THOMAS HARRISON E STEMPLE, 2008).

A relação entre a escala de resíduos em faringe e a assimetria das pregas vocais em repouso também foi estatisticamente significante, sendo que, quanto menores escores de resíduos em faringe menos assimetria das pregas vocais. A assimetria das pregas vocais são anormalidades laríngeas que podem estar altamente dependentes da localização do acontecimento do AVC. Especificamente no tronco encefálico alterações dos neurônios motores, tem como consequência, déficits laríngeos, que são caracterizados por voz é baixa com volume reduzido, perda do tônus muscular e dos reflexos (ATLMAN et al. 2007). Tais alterações podem ser recuperadas de acordo ao tempo do acontecimento e à plasticidade cerebral. (HUSSAIN et al., 1996). Demostrando assim, que os pacientes com menos ocorrência de alteração morfológica (pregas vocais), a função da faringe estava melhor também, possivelmente pela melhora do AVC.

Outra relação significante foi entre a escala de resíduos em faringe e a quantidade de aumento das pregas vestibulares (consistência pudim) e a constrição anteroposterior das aritenoides (consistência líquida). A presença de déficits sensoriais na faringe, decorrente de alteração das áreas sensoriais corticais, diminui os sinais do comando motor encarregado da ativar os músculos da orofaringe, o que prejudica o atraso da reposta da deglutição (AVIC et al. 1997), justificando a presença de resíduos na faringe. Em pacientes acometidos pelo AVC, segundo estudos, falhas no processo da deglutição fazem que o organismo gere medidas compensatórias para garantir uma eficiência e segurança na hora de engolir, sendo que como consequências a essas medidas podem surgem modificações morfológicas e comportamentais na laringe, como compensação (ANDRADE et al., 2009; VIANA et al., 2010; CAMPOS, 2013). 


\section{Discussão}

No caso desta pesquisa a constrição da aritenoides e o aumento das pregas vestibulares podem ser decorrentes do envelhecimento e que podem ter um papel positivo no processo de deglutição como mecanismo de proteção.

Não foi encontrada relação estatisticamente significante entre a escala de resíduos em seios piriformes e as características morfológicas e do comportamento laríngeo fonatório, o que indica uma homogeneidade nos resultados sem diferenciação alguma entre as relações. A pouca ocorrência de alterações laríngeas e da deglutição é atribuída à possível recuperação a pós estado agudo do AVC, tendo em vista que os exames foram realizados num estado tardio do acontecimento (ALTMAN et al. 2007).

Espera-se que os resultados mencionados acima, tragam contribuição a novos conceitos de avalição fonoaudiológica, permitindo ser referência de comparação com futuras pesquisas em na população idosa com AVC. Uma limitação nesta pesquisa pode ser atribuída ao número reduzido de pacientes analisados, já que na população idosa em estado tardio do AVC apresentam alguma recuperação fonoaudiológica, sendo este um fator de desinteresse dos para participar em pesquisas. 
6 Discussão 


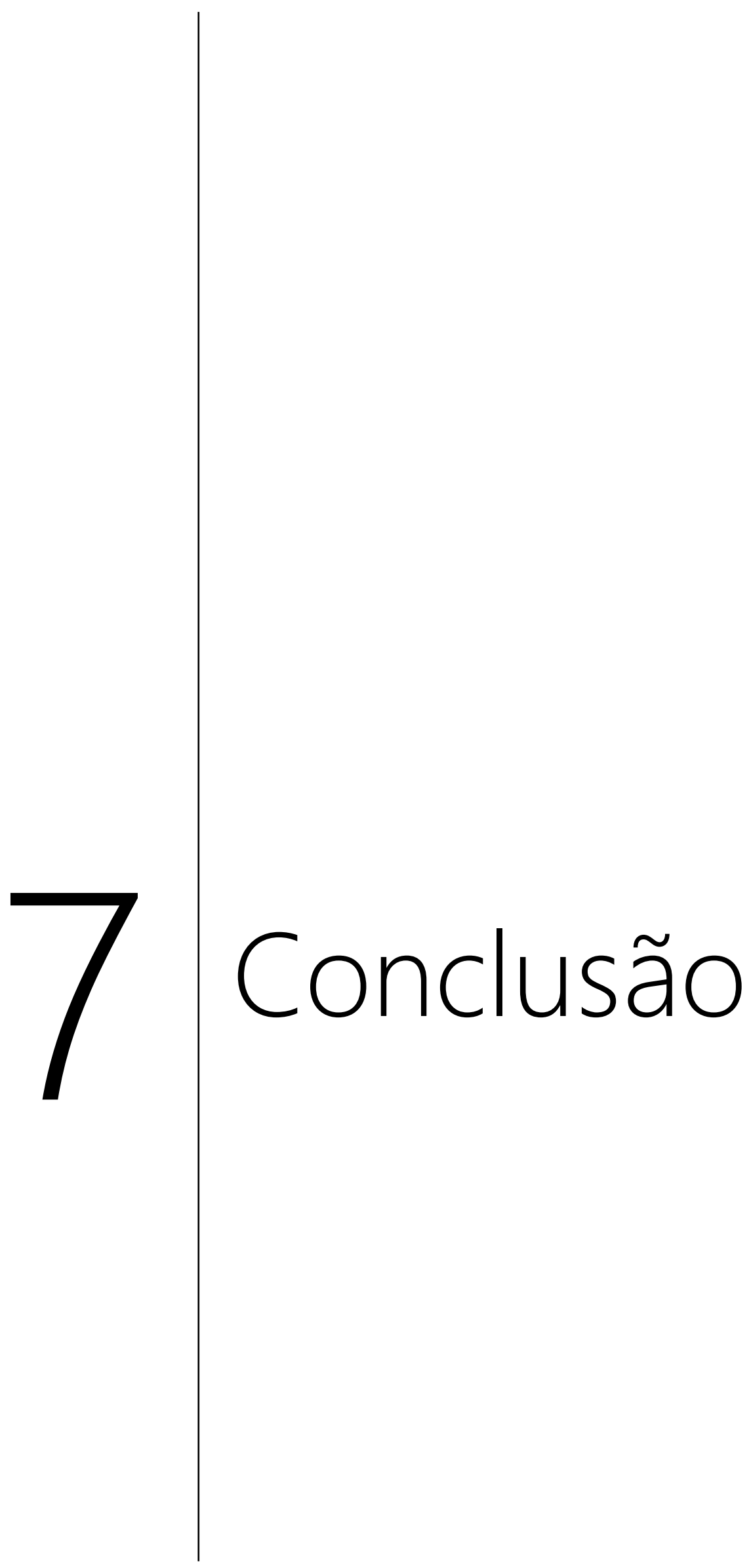







\section{CONCLUSÃO}

Concluiu-se que a característica laríngea fonatória constrição anteroposterior apresentou relação com aspectos de segurança e eficiência da deglutição, enquanto os aspectos assimetria de pregas vocais, quantidade de cobertura da epiglote e aumento das pregas vestibulares mostraram relação com a eficiência da deglutição em idosos na fase tardia do acometimento cerebral 



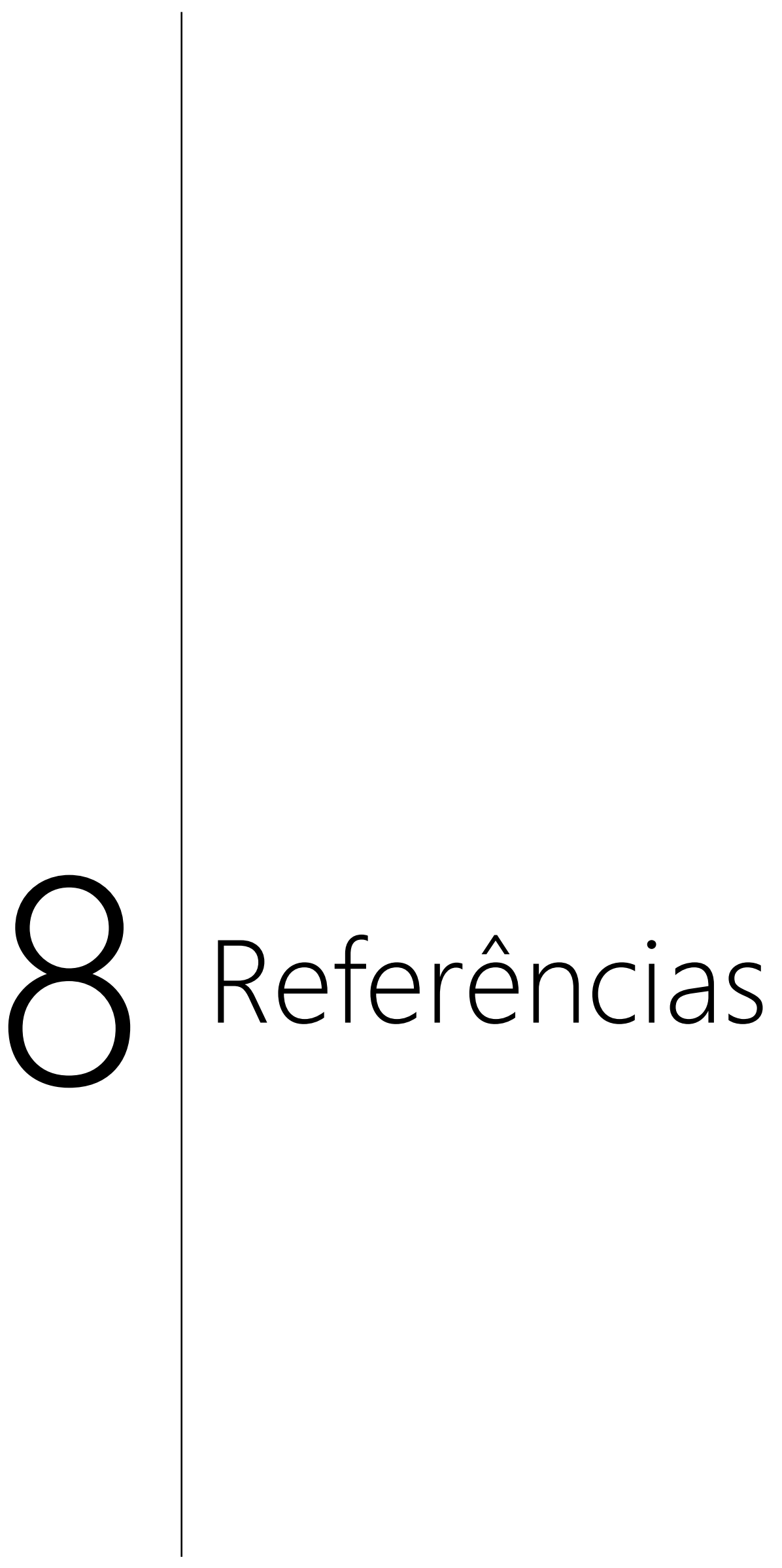





\section{REFERÊNCIAS}

Angerstein W. Stimm- und Kehlkopfveränderungen im Alter (Presbyphonie und Presbylarynx). Laryngo-Rhino-Otologie, 2018; 97(11), 772-776.

Andrade M, Cavalcante R, Haguette E. Achados da videoendoscopia da deglutição em adultos com disfagia orofaríngea neurogênica. Rev Soc Bras Fonoaudiol. 2009;14(3):454-62.

Altman Kenneth W, Schaefer Steven D, Yu Gou-Pei, Hertegard Stellan, Lundy Donna S, Blumin Joel H, Maronian Nicole C, Heman-Ackah Yolanda D, Abitbol Jean, Casiano Roy R. The voice and laryngeal dysfunction in stroke: A report from the Neurolaryngology Subcommittee of the American Academy of OtolaryngologyHead and Neck Surgery. Otolaryngology-Head and Neck Surgery (2007) 136, 873881.

Aviv JE, Sacco RL, Thomson J. Silent laryngopharyngeal sensory deficits after stroke. Ann Otol Rhinol Laryngol. 1997; 106: 87- 93.

Behlau M; Azevedo, R.; Pontes P. Conceito de voz normal e classificação das disfonias. In: Behlau, m. Voz: o livro do especialista, 1.rio de janeiro: revinter, 2001.

Bensenor I, Goulart A, Szwarcwald C, Pontes L, Carvalho D, Lufo P. Prevalence of stroke and associated disability in brazil: national healthsurvey. Arq Neuropsiquiatr 2015; 73(9):746-750.

Berretin-Felix G. Efeito da reabilitação oral implanto-suportada sobre a deglutição. O estado nutricional e a qualidade de vida de indivíduos idosos; tese. Botucatu: Faculdade de Medicina de Botucatu - Universidade Estadual Paulista: 2005.

Bezerra M; De Mello salves C. Disfagia estudo da reabilitação. Rio de Janeiro Livraria e editora Revinter Ltda. Cap. 1 Pág. 1.

Baer D. The natural history and functional consequences of dysphagia after hemispheric stroke. J Neurol Neurosurg Psychiatry 1993; 52: 236-41.

Boone D, Bayles K, Koopmann C. Communicative aspects of aging. Otolaryngol. Clind. North. Am. 1982; 15:313-27.

Campos P. Deglutição voz em idoso com sequelas de acidente vascular encefálico. 2013. Tese (Mestre em Ciências do programa de Fonoaudiologia) - Faculdade de Odontologia de Bauru, Universidade de São Paulo, Bauru, 2013. 
Carneiro R; Franco L. Acidente Vascular Cerebral. RevBrasHipertens 200; 8: 280-90.

Chang H, Torng P, Wang T, Chang Y.I. Acoustic Voice Analysis Does Notldentify Presence of Penetration/Aspiration as Confirmed by Videofluoroscopic Swallowing Study. ArchPhysMedRehabilVol 93, November 2012.

Chen M; Ott D; Peele V, Gelfand D. oroynx in patients with cerebrovascular disease: evaluation with videofluroscopy. Radiology. 1990; 176(3): 641-3.

Diez Tejedor E, et al. Clasificación de lasenfermedades cerebrovasculares. Sociedad Iberoamericana de Enfermedades Cerebrovasculares. RevNeurol. 2001; 33 (5): 455-464.

Eisenhuber E, Schima W, Schober E, Pokieser P, Stadler A, Scharitzer M, et al. Videofluroscopic assessment of patients with dysphagia: pharyngeal retention is a predictive factor of aspiration. AJR Am J Roentgenol. 2002;178(2):393-8.

Fernandes J, Brasolotto A, Berretin-Félix G, Yacubian A. Achados de neurorradiologia e voz no acidente vascular encefálico. CoDAS 2014; 26(2):168-74.

Gama A, Alves C, Cerceau J, Texeira L. Correlação entre dados perceptivosauditvos e qualidade de vida em voz de idosas. Rev Pró-Fono Atual. Cient, 2009; v.21, n 2, p. 125-130.

Gomes L. estudo da correlação entre a qualidade vocal e disfagia pós-acidente vasculara cerebral: aspectos acústicos, fisiológicos e perceptivos (Dissertação). São Paulo: Pontifícia Universidade Catológica de São Paulo; 2004.

Hussain Um , Woolfrey S, Massey J, Geddes A , Cox J . Gastrostomia endoscópica percutânea . Pós-graduação Med J 1996 ; $72: 581$ - 5.

Kelly AM, Leslie P, Beale T. Payten C. Drinnan M. Fibreoptic endoscopic evaluation of swalliwing and videofluoroscopy: does examination type influence perception of pharyngeal residue severityclin Otolaryngol. 2006; 31(5):425-32.

Kägi Georg, Leisi Natascha, Galovic Marian, Müller-Baumberger Marlise, Krammer Werner, Weder Bruno. Prolonged impairment of deglutition in supratentorial ischaemic stroke: the predictive value of Parramatta Hospitals' Assessment of Dysphagia. Swiss Med Wkly. 2016;146:w14355.

Logemann J, Pauloski B, Rademaker A. Temporal and biomechanical characteristics of oropharyngeal swallow in younger and older men. J Speech Lang Hear Res. 2000; 43: 1264-1274.

Marrara J. Pãdro visual da dinâmica vocal como instrumento para o diagnostico da disfagia em pacientes com alterações neurológicas. 2010. Tese (Mestre em 
Engenharia Elétrica) - Escola de Engenharia de São Carlos, Universidade de São Paulo, São Carlos, 2010.

Martins R, Pessin A, Nassib D. Aging voice and the laryngeal muscle atrophy. Laryngoscope, 2015; 125 pp. 2518-2521.

Montaldi M, Dantas R. Swallowing evaluation in patients without restriction of oral food three months after ischemic stroke. NeuroRehabilitation. 2019; 17. doi:10.3233/nre-192775

Mortelliti A, Malmgren L, Gacek R Ultrastructural changes with age in the human superior laryngeal nerve. Arch Otolaryngol Head Neck Surg. 1990; 116:1062-1069.

Muhle P, Wirth R, Glahn J et al Age-related changes in swallowing. Physiology and pathophysiology. Nervenarzt. 2015; 86:440-451.

Neubauer PD, Rademaker AW, Leder SB. The Yale pharyngeal residue severety rating scale: an anatomically defined anda image-based tool. Disphagya. 2015;30(5):521-8.

ORGANIZAÇÃO MUNDIAL DA SAUDE. Accidente cerebrovascular. Enfermedades cardiovasculares Nota descriptiva. 2015.

Paciaroni M, Mazzotta G, Corea F et al. Dysphagia following stroke. Eur Neurol 2004; 51: 162-7.

Pontes P; Brassolotto A; Behlau M. Glottic characteristics and voice com complaint in the elderly. JVoice. 2005. v.19, n.1, p.84-94.

Rodrigues T; Jacuviske M; Zazo K. Perfil populacional de pacientes com distúrbios da comunicação humana decorrentes de lesão cerebral, assistidos em hospital terciário. Rev. CEFAC2010; vol.13 no. 2.

Rofes L, Muriana D, Palomeras E, Vilardell N, Palomera E, Alvarez D, Berdugo. Casado V, Clavé P. Prevalence, risk factors and complications of oropharyngeal dysphagia in stroke patients: A cohort study. Neurogastroenterology \& Motility. 2018; 30:e13338.

Robbins J. Deglutição e envelhecimento normais. Semin Neurol. 1996; 16 (4): 309317.

Rosenbek JC, Robbins JÁ, Roecker EB, Coyle JL, Wood JL. A penetration-aspiration scale. Disphagia. 1996:11(2):93-B.Rosow D, Pan D. Presbyphonia and Minimal Glottic Insufficiency. Otolaryngologic Clinics of North America, 2019; 52 (4), 617-25. 
Silva RG. Disfagia orofaríngea neurogênica: videofluoroscopia e videoendoscopia da deglutição com aplicação de técnicas terapêuticas fonoaudiologicas. Tess. Botucatu: Faculdade de Medicina de Botucatu - UNESP; 2002.

Siquiera LTD. Impacto dos aspectos respiratorios e vocais na qualidade de vida do idoso (dissertação). Bauru: Universidade de São Paulo, Faculdade de Ontologia de Bauru; 2013.

Suárez J, Restrepo S, Ramírez E Bedoya L, Jiménez I. Descripción clínica, social, laboral y de lapercepción funcional individual en pacientes con ataque cerebrovascular. Acta NeurolColomb. 2011. Vol. 27 No. 2 Junio.

Thomas L, Harrison A, Stemple J. Aging thyroarytenoid and limb skeletal muscle: a review. J voice, v. 22, n. 4, p. 430-50, 2008.

Thrift A. Global Stroke Statistics International. Journal of Stroke 2017, Vol. 12(1) 1332.

Viana A, Olivera R, Ramos S, Cabette F. Avaliação fonoaudiológica e cintilográfica da deglutição de pacientes pós-acidente vascular encefálico. Pró-Fono Revista de Atualização Científica, v.22, n.3, p.317-324, 2010.

Vilardell N, Rofes L, Arreola V Martin A, Muriana D, Palomeras E, Ortega O, Clavé P. Videofluoroscopic assessment of the pathophysiology of chronic poststroke oropharyngeal dysphagia. Neurogastroenterology \& Motility. 2017;29:e13111.

Weber K, Scheeren B, Maciel A, Cassol M. Vocal variability post swallowing in individuals with and with out oropharyngeal dysphagia. Int Arch Otorhinolaryngol 2015;19:61-66.

Yamasaki R. Caracterização da laringe do idoso. Tese. São Paulo. Universidade Federal de São Paulo - Escola Paulista de Medicina; 2001.

Yamauchi Akihito, Imagawa Hirosh, Yokonishi Hisayuki, Nito Takaharu, Yamasoba Tatsuya, Goto Takao, Takano Shingo Sakakibara, Ken-Ice, Tayama Niro. Evaluation of Vocal Fold Vibration With an Assessment Form for High-Speed Digital Imaging: Comparative Study between Healthy Young and Elderly Subjects. Japan. Journal of Voice, Vol. 26, No. 6.

Yamamoto, S. Tanaka, H. Tsubone. Age-related changes in sensory and secretomotor nerve endings in the larynx of $\mathrm{F} 344 / \mathrm{N}$ rat Arch Gerontol Geriatr, 36 (2) (2003),

pp. 173-183 



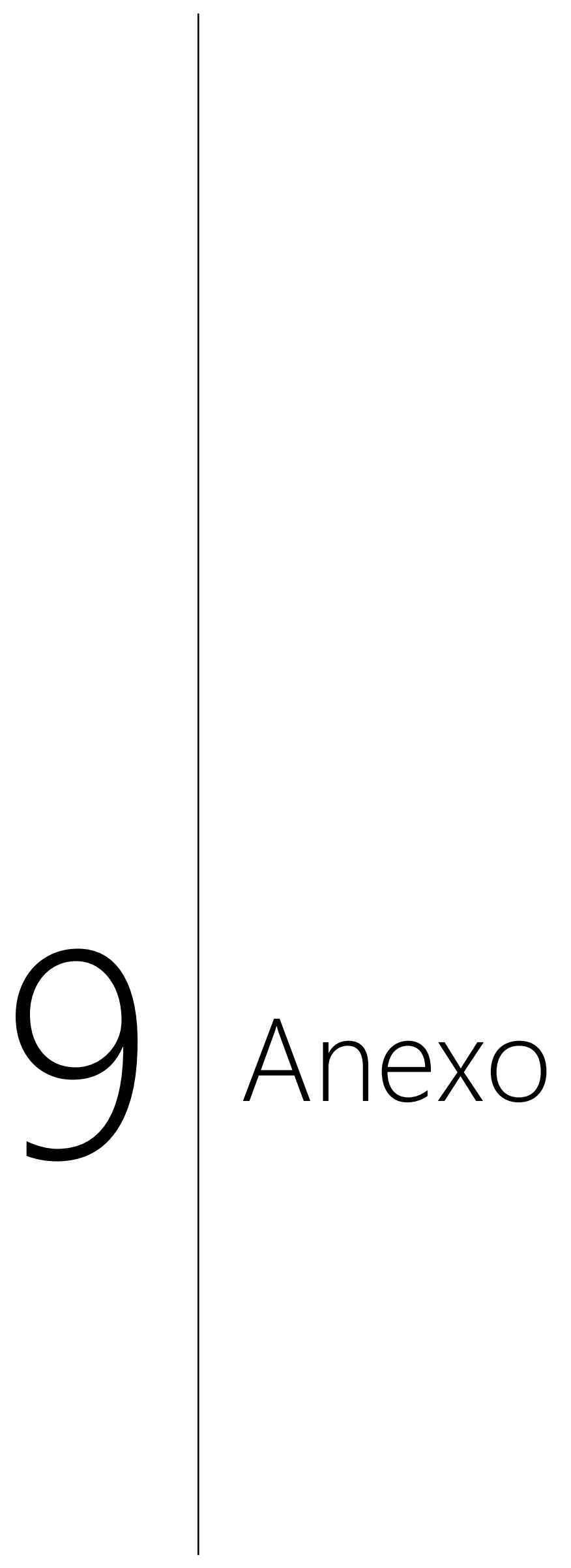






\section{Anexos}

Anexo

1.

USP - FACULDADE DE
ODONTOLOGIA DE BAURU DA Q Pratil
USP
PARECER CONSUBSTANCIADO DO CEP

DADOS DO PROJETO DE PESQUISA

Título da Pesquisa: CARACTERISTICAS LARÍNGEAS, DEGLUTIÇÄO E FONOARTICULAÇÄO EM IDOSOS PÓS-ACIDENTE VASCULAR CEREBRAL

Pesquisador: Jonan Emi Valencia Cardenas

Área Temática:

Versäo: 2

CAAE: 97392318.0 .0000 .5417

Instituiçäo Proponente:Universidade de Sao Paulo

Patrocinador Principal: Financiamento Próprio

\section{DADOS DO PARECER}

Número do Parecer: 2.976 .893

Apresentação do Projeto:

idem parecer numero 2.816 .804

Objetivo da Pesquisa:

idem parecer numero 2.816 .804

Avaliaçäo dos Riscos e Beneficios:

idem parecer numero 2.816 .804

Comentários e Consideraçöes sobre a Pesquisa:

idem parecer numero 2.816 .804

Consideraçöes sobre os Termos de apresentação obrigatória:

idem parecer numero 2.816 .804

Conclusões ou Pendências e Lista de Inadequações:

De acordo com as pendencias registradas, os pesquisadores atenderam a correção dos riscos e esclareceram on da pesquisa no projeto e na $\mathrm{PB}$.

Lembrando aos pesquisadores, que como solicitado na pendencia anterior, em relaçăo a justificatica da dispensa do TCLE, foi solicitado que os pesquisadores acrescentassem no texto a "garantia a nåo exposição dos dados dos prontuarios bem

como o zelo aos prontuarios" (vide parecer consubstanciado numero 2.816 .804 no campo pendencias). Assim sendo, percebemos que o novo documento anexado năo contempla os dizeres.

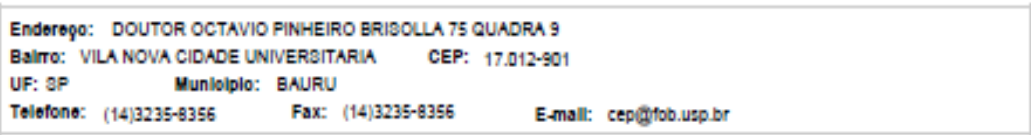




USP - FACULDADE DE
ODONTOLOGIA DE BAURU DA
USP

Corthuaçso do Parecer. 2078.509

Solicitamos que os pesquisadores façam o ajuste documento, antes do termino da pesquisa, em forma de emenda.

Consideraçöes Finais a critério do CEP:

Esse projeto foi considerado APROVADO na reunião ordinária do CEP de 10/10/2018, com base nas normas éticas da Resolução CNS 466/12. Ao término da pesquisa o CEP-FOB/USP exige a apresentação de relatório final. Os relatórios parciais deverão estar de acordo com o cronograma e/ou parecer emitido pelo CEP. Alterações na metodologia, título, inclusão ou exclusão de autores, cronograma e quaisquer outras mudanças que sejam significativas deverão ser previamente comunicadas a este CEP sob risco de näo aprovação do relatório final. Quando da apresentaçäo deste, deveräo ser incluidos todos os TCLEs elou termos de doaçäo assinados e rubricados, se pertinentes.

Este parecer foi elaborado baseado nos documentos abaixo relacionados:

\begin{tabular}{|c|c|c|c|c|}
\hline Tipo Documento & Arquivo & Postagem & Autor & Situaçăo \\
\hline $\begin{array}{l}\text { Informaçóes Básicas } \\
\text { do Projeto }\end{array}$ & $\begin{array}{l}\text { PB_INFORMAÇOES_BASICAS_DO_P } \\
\text { ROJETO } 1171470 \text {.pdf }\end{array}$ & $\begin{array}{c}27 / 09 / 2018 \\
10: 45: 02\end{array}$ & & Aceito \\
\hline \begin{tabular}{|l|} 
Projeto Detalhado / \\
Brochura \\
Investigador
\end{tabular} & Projeto.doc & $\begin{array}{c}27 / 09 / 2018 \\
10: 44: 44\end{array}$ & $\begin{array}{l}\text { Jonan Emi Valencia } \\
\text { Cardenas }\end{array}$ & Aceito \\
\hline Outros & solicitacao_dispensa_TCLE.pdf & $\begin{array}{c}27 / 09 / 2018 \\
10: 31-52\end{array}$ & $\begin{array}{l}\text { Jonan Emi Valencia } \\
\text { Cardenas }\end{array}$ & Aceito \\
\hline Outros & cartadeaquiescencia.pdf & $\begin{array}{l}13 / 08 / 2018 \\
20: 26: 14\end{array}$ & $\begin{array}{l}\text { Jonan Emi Valencia } \\
\text { Cardenas }\end{array}$ & Aceito \\
\hline Outros & cartadeaquiescenciadodepto.pdf & $\begin{array}{c}13 / 08 / 2018 \\
20: 25: 12\end{array}$ & $\begin{array}{l}\text { Jonan Emi Valencia } \\
\text { Cardenas }\end{array}$ & Aceito \\
\hline Outros & QTDP.doc & $\begin{array}{c}18 / 07 / 2018 \\
13: 11: 41\end{array}$ & $\begin{array}{l}\text { Jonan Emi Valencia } \\
\text { Cardenas }\end{array}$ & Aceito \\
\hline Outros & TADF.pdf & $\begin{array}{c}18 / 07 / 2018 \\
12: 55-10\end{array}$ & $\begin{array}{l}\text { Jonan Emi Valencia } \\
\text { Cardenas }\end{array}$ & Aceito \\
\hline $\begin{array}{l}\text { Declaraçáo de } \\
\text { Pesquisadores }\end{array}$ & DCC.pdf & $\begin{array}{c}18 / 07 / 2018 \\
12: 53: 10\end{array}$ & $\begin{array}{l}\text { Jonan Emi Valencia } \\
\text { Cardenas }\end{array}$ & Aceito \\
\hline Folha de Rosto & folha.pdf & $\begin{array}{c}18 / 07 / 2018 \\
12: 42: 31\end{array}$ & $\begin{array}{l}\text { Jonan Emi Valencia } \\
\text { Cardenas }\end{array}$ & Aceito \\
\hline
\end{tabular}

Situação do Parecer:

Aprovado

Necessita Apreciação da CONEP:

EMJOrOQO: DOUTOR OCTAVIO FINHEIRO ERIOOLLA 75 QUADRA 9

BaITO: VILA NOWA CIDADE UNIVERITARIA CEP: 17.012-901

UF: 3P : Munlolplo: BAURU (14)3235-8356

E-mall: cepgrtob.usp.br 
USP - FACULDADE DE

ODONTOLOGIA DE BAURU DA USP

Cortihuaç̧o do Parecer: 2.978 .603

Não

BAURU, 23 de Outubro de 2018

Assinado por:

Ana Lúcia Pompéia Fraga de Almeida

(Coordenador(a))

ENderopO: DOUTOR OCTAVIO FINHEIRO BRIOOLLA 75 QUADRA 9

BaITO: VILA NOVA CIDADE UNIVERITARIA CEP: $17.012-901$

UF: aP Munlolplo: BAURU

Telefone: (14)3235-8356 Fax: (14)3235-8356

E-mall: cepegrob.usp.br 